\title{
Chalcogen Bonding Macrocycles and [2]Rotaxanes for Anion Recognition
}

\author{
Jason Y. C. Lim ${ }^{\mathrm{a}}$, Igor Marques ${ }^{\mathrm{b}, \mathrm{c}}$, Amber L. Thompson ${ }^{\mathrm{a}}$, Kirsten E. Christensen ${ }^{\mathrm{a}}$, Vítor Félix ${ }^{\mathrm{b}, \mathrm{c}}$ and \\ Paul D. Beer ${ }^{\mathrm{a}, *}$ \\ ${ }^{\text {a }}$ Chemistry Research Laboratory, Department of Chemistry, University of Oxford, Mansfield Road, Oxford, OX1 3TA \\ (UK). Email: paul.beer@chem.ox.ac.uk. ${ }^{b}$ Department of Chemistry, CICECO - Aveiro Institute of Materials, University of \\ Aveiro, 3810-193 Aveiro, Portugal. ${ }^{\mathrm{c}}$ Department of Medical Sciences, iBiMED - Institute of Biomedicine, University of \\ Aveiro, 3810-193 Aveiro, Portugal.
}

\begin{abstract}
Electron-deficient heavy chalcogen atoms contain Lewis acidic $\sigma$-holes which are able to form attractive supramolecular interactions, known as chalcogen bonding $(\mathrm{ChB})$, with Lewis bases. However, their potential in solution-phase anion binding applications is only just beginning to be realized in simple acyclic systems. Herein, we explore the 5-(methylchalcogeno)-1,2,3triazole (chalcogen $=\mathrm{Se}, \mathrm{Te}$ ) motif as a novel $\mathrm{ChB}$ donor for anion binding. Other than being chemically-robust enough to be incorporated into macrocyclic structures, thereby significantly expanding the scope and complexity of ChB host systems, we also demonstrate, by ${ }^{1} \mathrm{H}$ NMR and DFT calculations, that the chalcogen atoms oriented within the macrocycle cavity are able to chelate copper(I) endotopically. Exploiting this property, the first examples of mechanically-interlocked [2]rotaxanes containing ChBdonor groups are prepared via an active metal template strategy. Solution-phase ${ }^{1} \mathrm{H}$ NMR and molecular modelling studies provide compelling evidence for the dominant influence of $\mathrm{ChB}$ in anion binding by these interlocked host systems. In addition, unprecedented charge assisted ChB-mediated anion binding was also studied in aqueous solvent mixtures which revealed considerable differences in anion recognition behavior in comparison with chalcogen-free host analogues. Moreover, DFT calculations and Molecular Dynamics simulations in aqueous solvent mixtures indicate that the selectivity is determined by the different hydrophilic character of the anions allied to the hydration of the binding units in the presence of the anions. Exploiting the NMR-active nuclei of the ChB-donor chalcogen atoms, heteronuclear ${ }^{77} \mathrm{Se}$ and ${ }^{125} \mathrm{Te}$ NMR was used to directly study how anion recognition influences the local electronic environment of the chalcogen atoms in the mechanically bonded rotaxane binding sites in organic and aqueous solvent mixtures
\end{abstract}

\section{INTRODUCTION}

Chalcogen bonding $(\mathrm{ChB})$, the attractive non-covalent interaction between an electrophilic Group 16 element ( $\mathrm{S}, \mathrm{Se}$ and $\mathrm{Te}$ ) and a Lewis base, is a member of a wider class of sigma holebased interactions which also include the more familiar halogen bonding. ${ }^{1,2}$ Electron withdrawing groups covalently attached to the chalcogen atom anisotropically re-distributes the electron density on the atom itself, forming electron deficient sigma holes which can act in a Lewis acidic manner. Consequently, either one or two sigma holes may form on a $s p^{2}$ or $s p^{3}$ - hybridised chalcogen atom respectively, with important ramifications on the geometry of the resulting chalcogen $\cdots$ Lewis base interaction. ${ }^{3,4}$ Owing to their unique highlydirectional geometrical requirements and comparable strength to ubiquitous hydrogen bonding (HB) interactions, ${ }^{5,6}$ chalcogen bonding has found recent applications in organic reactivity, ${ }^{7-9}$ materials and crystal engineering, ${ }^{10,11}$ anion transportation, ${ }^{12}$ self-assembly processes ${ }^{13-15}$ and pharmaceutics. ${ }^{16} \mathrm{Nev}-$ ertheless, compared to the more widely-studied sister noncovalent halogen bonding interaction, ${ }^{17,18}$ solution-phase studies involving $\mathrm{ChB}$ systems are extremely rare, with their potential for anion binding only recently realised. ${ }^{19-21}$ This is in part due to the inherent chemical instability of compounds bearing the heavier chalcogens, which in spite of their enhanced $\mathrm{ChB}$-donor properties, are often highly prone to oxidative decomposition and hydrolysis, ${ }^{19,22}$ thus limiting their incorporation into more complex host structures and thwarting attempts to study their binding properties in more competitive protic/ aqueous solvents. To the best of our knowledge, the incorporation of $\mathrm{ChB}$ donor groups into elaborate host structures such as macrocycles and mechanically-interlocked molecules for anion recognition applications is unprecedented.

To address the dearth of chemically robust and stable $\mathrm{ChB}$ motifs for anion recognition, we report herein the synthesis of readily-accessible 5-(methylchalcogeno)-1,2,3-triazole $\mathrm{ChB}$ motifs $($ chalcogen $=\mathrm{Se}, \mathrm{Te})$. Other than polarizing the chalcogen atoms strongly for potential $\mathrm{ChB}$-anion interactions, the potent electron-withdrawing nature of the triazole unit also helps to stabilize the chalcogen atoms by reducing their electron density and thus, propensity for oxidation and hydrolysis. ${ }^{23}$ Indeed, these $\mathrm{ChB}$ donor motifs were found to be chemically stable enough to withstand the various chemical manipulations required for integration into macrocyclic structures. Within the macrocycle, the chalcogen atoms were also observed to exhibit both Lewis acid and Lewis base behavior, binding anions as well as coordinating metal cations such as 
copper(I). Exploiting endotopically-bound copper(I) within the $\mathrm{ChB}$ macrocycles, active-metal templation ${ }^{24}$ is used to construct a series of selenium and tellurium-containing $\mathrm{ChB}$ [2]rotaxanes (Scheme 1). Solution-phase ${ }^{11} \mathrm{H},{ }^{77} \mathrm{Se}$ and ${ }^{125} \mathrm{Te}$ NMR spectroscopy, as well as molecular modelling studies, provide compelling evidence for the dominant influence of $\mathrm{ChB}$ in anion binding by these interlocked host systems. In addition, post-rotaxane $N$-methylation of the selenotriazole motifs produced cationic interlocked rotaxane host systems capable of hitherto-unknown charge-assisted ChB-mediated anion recognition in aqueous solvent mixtures.

\section{RESULTS AND DISCUSSION}

Design and Synthesis of Chalcogen Bonding Macrocycles. Macrocycles containing two methylchalcogeno-triazoles covalently attached to a central benzene spacer at the 1,3-positions were designed to favor chelated $\mathrm{ChB}$-anion interactions (see Scheme 1).

Conventionally, the synthesis of macrocycles containing prototriazole units can be achieved using the copper(I)catalysed azide-alkyne cycloaddition (CuAAC) reaction involving appropriately-functionalised azides and terminal alkynes in the crucial ring-closing step. ${ }^{25,26}$ However, the synthesis of chalcogen-functionalised triazoles directly from alkynes remains highly challenging. While seleno-triazoles can be produced from both terminal alkynes ${ }^{27}$ and seleniumsubstituted internal alkynes, ${ }^{28}$ these methods require either harsh conditions with heating in excess of $100{ }^{\circ} \mathrm{C}$ or highlyspecialized reagents and noble metal catalysts. On the other hand, telluro-triazoles are even more demanding synthetic targets due to the weaker C-Te bond (bond energy of c.a. 200 $\mathrm{kJ} \mathrm{mol}^{-1}$ compared to $234 \mathrm{~kJ} \mathrm{~mol}^{-1}$ for $\left.\mathrm{C}-\mathrm{Se}\right),{ }^{22}$ rendering them more thermally labile and prone to oxidative metal insertion. ${ }^{29,30}$ As such, methods to synthesize them, such as a recent example using tellurium-functionalised internal alkynes, ${ }^{30}$ are rare. Due to these difficulties precluding the use of CuAAC for ring-closure, an alternative ring-closing approach was investigated where bis-phenol $\mathbf{2}$, pre-functionalized with methylchalcogeno-triazole moieties, was reacted with triethylene glycol-bistosylate $\mathbf{3}$ under basic conditions to form the desired macrocycles (Scheme 2A).
To synthesise 2 (chalcogen $=\mathrm{Se} / \mathrm{Te}$ ), a novel general route was pursued where the methylchalcogeno-triazoles were assembled from a common 5-iodo-1,2,3-triazole starting material using readily-available reagents. Using a one-pot 'iodoClick' procedure, ${ }^{31}$ the reaction of two equivalents of azide 4 and 1,3-diethynylbenzene afforded the bis-iodotriazole 5 intermediate in excellent yield (Scheme 2B). Combining elemental tellurium and methyl lithium then generated the strongly nucleophilic methyl telluride ( $\mathrm{MeTe}^{-}$) anion in situ, which on reaction with $\mathbf{5}$, afforded methyltelluro-triazole 6.Te in 82 $\%$ yield following chromatographic purification. ${ }^{32}$ An analogous procedure where lithium methyl selenide was reacted with 5 surprisingly only produced bis-methylseleno-triazole 6.Se in low yields $(<5 \%)$. However, converting the iodotriazole motifs first to fluorotriazoles using Fokin's halogen exchange protocol ${ }^{33}$ gave bis-fluorotriazole 7, which upon reaction with lithium methyl selenide, afforded 6.Se in an overall yield of $46 \%$ starting from $\mathbf{5}$. Following quantitative conversion of 6.Se/Te to the bis-phenol macrocycle precursors 2.Se/Te by acidic methoxymethyl acetal deprotection, reacting 2.Se/Te with triethylene glycol-bistosylate 3 using cesium carbonate as base then produced the macrocycles 1.Se/Te (Scheme 2B) (see Supporting Information for full synthetic procedures and characterization data). ${ }^{34}$

Interactions of ChB Macrocycles with Copper(I). The active metal templation approach has been successfully used in the construction of a variety of mechanically bonded molecules, where a transition metal such as copper, ${ }^{35-44}$ palladi$\mathrm{um}^{45,46}$ or nickel, ${ }^{47}$ coordinated within the cavity of a macrocycle orientates and catalyses covalent bond formation between appropriately-functionalised half-axle or ring precursor components. We envisaged using copper(I) active metal templation to synthesize $\mathrm{ChB}$ rotaxanes via the metal's coordination by the $\mathrm{ChB}$ macrocycles 1.Se/Te and $\mathrm{CuAAC}$ reaction between terminal azide and alkyne axle precursors. Hence, we first established the possibility of $\mathrm{Cu}(\mathrm{I})$ binding endotopically within the $\mathrm{ChB}$ macrocycles.

${ }^{1} \mathrm{H}$ NMR titrations were performed where increasing quantities of $\left[\mathrm{Cu}\left(\mathrm{CH}_{3} \mathrm{CN}\right)_{4}\right] \mathrm{PF}_{6}$ were added to separate solution of macrocycles 1.Se and 1.Te in $\mathrm{CD}_{2} \mathrm{Cl}_{2}$. In the presence of 1.0 equivalent of $\mathrm{Cu}(\mathrm{I})$,

Scheme 1. Active Metal Template Strategy for Synthesis of Chalcogen Bonding [2]Rotaxanes
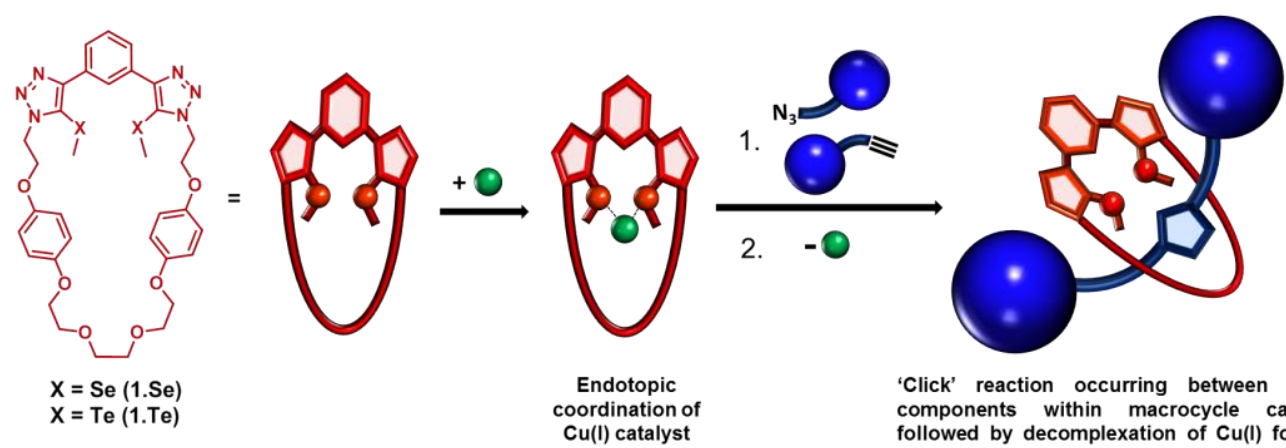

Endotopic

coordination of $\mathrm{Cu}(\mathrm{l})$ catalyst
within macrocycle
'Click' reaction occurring between axle components within macrocycle cavity followed by decomplexation of $\mathrm{Cu}(\mathrm{l})$ forms neutral $\mathrm{ChB}$ rotaxanes 
Scheme 2. Retrosynthetic strategy and forward synthesis of ChB macrocycles 1.Se/Te.

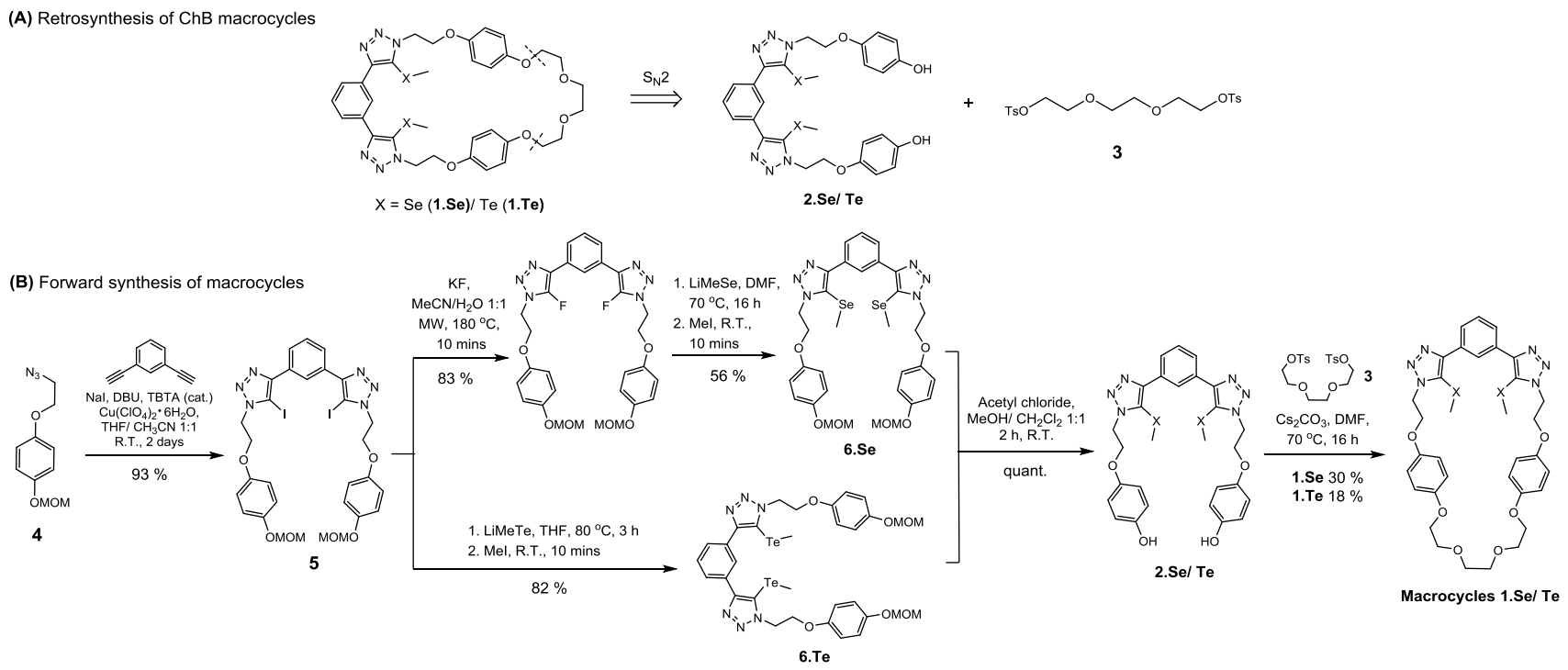

the ${ }^{1} \mathrm{H}$ NMR spectrum of $\mathbf{1 . S e}$ retained its symmetry, with upfield perturbations observed for signals corresponding to the central benzene ring $\left(\mathrm{H}_{\mathrm{a}}, \mathrm{H}_{\mathrm{b}}\right.$ and $\left.\mathrm{H}_{\mathrm{c}}\right)$ between the selenotriazole moieties, accompanied by downfield shifts of $\mathrm{H}_{\mathrm{d}}, \mathrm{H}_{\mathrm{e}}$, hydroquinones and SeMe units (Figure 1A). Increasing spatial separation from the seleno-triazole units resulted in smaller movements of the proton signals, with no shifts observed for the polyether environments on the other end of the macrocycle. This was clearly indicating that $\mathrm{Cu}(\mathrm{I})$ was binding to the macrocycle's seleno-triazole motifs. Similarly, macrocycle 1.Te also retained its ${ }^{1} \mathrm{H}$ NMR spectral symmetry in the presence of 1.0 equivalent of $\mathrm{Cu}(\mathrm{I})$ (see Supporting Information).

To elucidate the role played by the chalcogen atoms in $\mathrm{Cu}$ (I)-binding, an analogous titration was performed using the chalcogen-free analogue (1.HB) of the $\mathrm{ChB}$ macrocycles (see Supporting information for synthesis of 1.HB). Surprisingly, the presence of 1.0 equivalent of $\mathrm{Cu}(\mathrm{I})$ resulted in loss of symmetry of 1.HB's NMR spectrum: the originally equivalent environments of $\mathrm{H}_{B}$ and the triazoles $\left(\mathrm{H}_{\mathrm{D}}\right)$ were now split into separate and distinct signals, with the hydroquinones now split into four well-resolved doublets (Figure 1B). The perturbations of the triazole signals were especially telling, with one signal showing a large upfield shift $(\Delta \delta=-0.40 \mathrm{ppm})$ and the other giving a downfield shift of $+0.11 \mathrm{ppm}$ - the latter consistent with direct $\mathrm{Cu}(\mathrm{I})$ coordination to a nitrogen atom of only one of the triazoles at any one time. ${ }^{48}$ Importantly, this finding implied that the triazole units of the benzene-1,3bis(triazole) motif are too far apart spatially to allow concomitant bidentate $\mathrm{Cu}(\mathrm{I})$-coordination to the nitrogen atoms of both triazole moieties, which would have resulted in the ${ }^{1} \mathrm{H}$ NMR spectrum of macrocycle 1.HB retaining its symmetrical nature (vide infra). Further differences in the $\mathrm{Cu}(\mathrm{I})$-binding properties of the $\mathrm{ChB}$ macrocycles and $\mathbf{1 . H B}$ were seen using UV-Vis spectroscopy in dichloromethane. With 1.HB, a distinct enhancement in the absorbance was observed at $290 \mathrm{~nm}$ with the addition of $\left[\mathrm{Cu}\left(\mathrm{CH}_{3} \mathrm{CN}\right)_{4}\right] \mathrm{PF}_{6}$, which has been previously shown to arise from direct triazole $N$-coordination to $\mathrm{Cu}(\mathrm{I})$, perturbing their frontier molecular orbital energy levels. ${ }^{48,49}$ In contrast, analogous titrations performed with 1.Se and 1.Te show negligible optical changes (see Supporting Information Section S4.2). Given the optical sensitivity of triazole absorbance to $N$-ligation and considering our ${ }^{1} \mathrm{H}$ NMR titrations, these observations suggest that 1.Se and 1.Te are coordinating $\mathrm{Cu}(\mathrm{I})$ via the chalcogen atoms themselves. Further evidence for direct chalcogen-coordination was obtained from

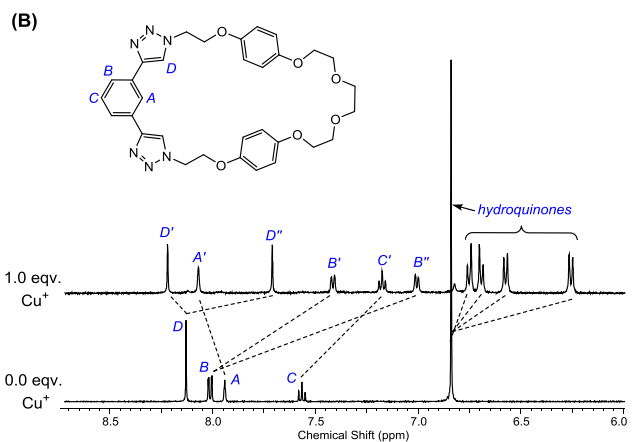

Figure 1. Partial ${ }^{1} \mathrm{H}$ NMR spectra showing macrocycles (A) 1.Se in $d_{6}$-acetone and (B) $\mathbf{1 . H B}$ in $\mathrm{CD}_{2} \mathrm{Cl}_{2}$ in the presence of 0.0 and 1.0 equivalents of $\mathrm{Cu}\left(\mathrm{CH}_{3} \mathrm{CN}\right)_{4} \mathrm{PF}_{6}(500 \mathrm{MHz}, T=298 \mathrm{~K})$. 
heteronuclear ${ }^{77} \mathrm{Se}$ and ${ }^{125} \mathrm{Te}$ NMR studies, where the addition of $\mathrm{Cu}(\mathrm{I})$ led to complete loss of their distinct initial signals $\left(\delta_{\mathrm{Se}}=47 \mathrm{ppm}\right.$ for 1.Se; $\delta_{\mathrm{Te}}=146 \mathrm{ppm}$ for 1.Te $)$, likely due to signal-broadening arising from direct ${ }^{l} J$-coupling to the quadrupolar $\mathrm{Cu}(\mathrm{I})$ nuclei $\left(I=3 / 2\right.$ for both ${ }^{63} \mathrm{Cu}$ and $\left.{ }^{65} \mathrm{Cu}\right)$. As direct $\mathrm{Cu}(\mathrm{I})$ coordination to $\mathrm{Se}$ or Te atoms are known, ${ }^{50-55}$ our findings strongly suggest that $\mathrm{Cu}(\mathrm{I})$ is coordinated endotopically within the macrocycles via both chalcogen atoms simultaneously, accounting for the retention of symmetry seen in the ${ }^{1} \mathrm{H}$ NMR titrations using 1.Se and 1.Te.

Additional support for the ChB macrocycles' bidentate coordination of $\mathrm{Cu}(\mathrm{I})$ was provided by DFT simulations. Using two possible models of the 1.Se-Cu(I) complex, where the methylchalcogeno- units were either facing into (model $A$ ) or outside (model $B$ ) the macrocycle cavity, we investigated the possibility of bidentate $\mathrm{Cu}(\mathrm{I})$ coordination by either both $\mathrm{Se} / \mathrm{Te}$ or $\mathrm{N}$ atoms of the chalcogeno-triazoles by placing a $\mathrm{Cu}(\mathrm{I})$ cation equidistant from both atoms. After completing the tetrahedral coordination sphere of $\mathrm{Cu}(\mathrm{I})$ with two acetonitrile molecules, these structures were then optimized by DFT with the Gaussian09 package, ${ }^{56}$ using the B3LYP functional and the $6+31 \mathrm{G}^{* *}$ basis set for the $\mathrm{H}, \mathrm{C}, \mathrm{N}$ and $\mathrm{O}$ atoms and the aug-cc-pVDZ-PP basis set, ${ }^{57,58}$ for the $\mathrm{Se}, \mathrm{Te}$ and $\mathrm{Cu}$ centers. The acetone solvent effects were further taken into account through the Polarizable Continuum Model (PCM), using the integral equation formalism variant (IEFPCM). ${ }^{59}$

As shown in Figure 2A, the optimized structures of the 1.Se- $\mathrm{Cu}(\mathrm{I})$ complexes using model $A$ show retention of the initial $\mathrm{Cu}(\mathrm{I})$ tetrahedral coordination environment, with both selenium atoms binding the $\mathrm{Cu}(\mathrm{I})$ in a bidentate manner. An identical coordination mode was seen for 1.Te as well (see Figure S7-1 Supporting Information). The calculated bond lengths of $\mathrm{Cu}-\mathrm{Se}(2.561$ and $2.594 \AA)$ and $\mathrm{Cu}-\mathrm{Te}(2.669$ and $2.693 \AA$ ) agree well with those of known structures in the Cambridge Structural Database (CSD). ${ }^{60}$ In addition, the computed structural parameters (bond lengths and bond angles) for both complexes, as summarized in Table S7-1 of the Supporting Information, show definitively that the macrocycles are able to endotopically coordinate $\mathrm{Cu}(\mathrm{I})$ in a bidentate manner, corroborating our aforementioned solution-phase spectroscopic evidence.

In stark contrast, DFT optimization of the $N$-ligated copper complexes of 1.Se and 1.Te (model $B$ ) showed loss of the initial bidentate coordination mode (Figure 2B), with clear indication that decomplexation has occurred, with the macrocycles adopting a monodentate coordination mode, as shown by the large computed distances between the metal center and the $N$ atom of the second triazole unit (4.573 $\AA$ for 1.Se and $4.638 \AA$ for 1.Te) (see Figure S7-1 and Table S7-2 in Supporting Information). Furthermore, from the larger optimized distances between the triazole $\mathrm{N}^{3}$ atoms for model $B(N-N$ distance $=5.376$ and $5.422 \AA$ for 1.Se and 1.Te respectively) compared to the chalcogen-chalcogen distances for model $A$ (4.654 $\AA$ for 1.Se and $4.638 \AA$ for 1.Te), the bidentate endotopic chalcogen coordination of $\mathrm{Cu}(\mathrm{I})$ of model $A$ would result in lower steric strain compared with the hypothetic scenario of model $B$ involving the simultaneous ligation by both triazole $\mathrm{N}^{3}$ atoms. Hence, the former binding scenario is more likely to occur in solution with both macrocycles 1.Se and 1.Te.
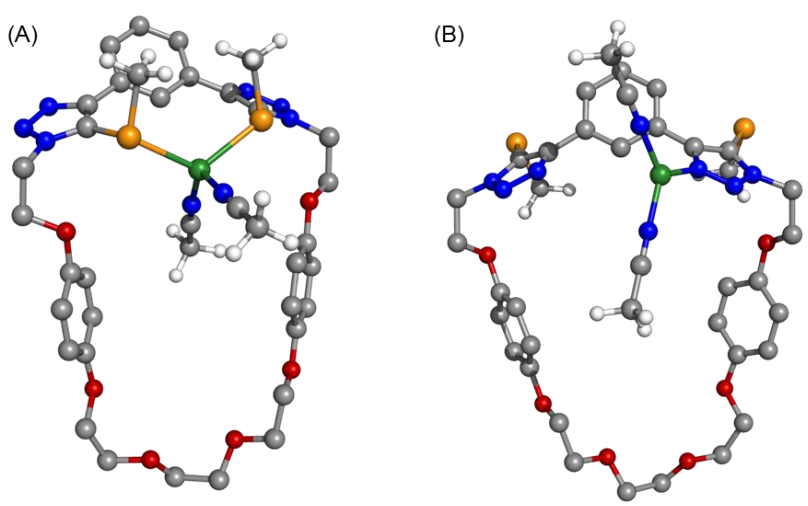

Figure 2. DFT optimized structures of the possible coordination modes of $\left[\mathrm{Cu} \text { 1.Se }\left(\mathrm{CH}_{3} \mathrm{CN}\right)_{2}\right]^{+}$complex using (A) model A and (B) model B.

Active-metal Template Synthesis of Neutral ChB [2]Rotaxanes. With the ability of the $\mathrm{ChB}$ macrocycles to bind $\mathrm{Cu}(\mathrm{I})$ within their cavities established, the synthesis of neutral ChB [2]rotaxanes following the active metal template strategy was undertaken. An equimolar mixture of each $\mathrm{ChB}$ or $\mathrm{HB}$ macrocycle $(\mathbf{1 . S e} / \mathbf{T e} / \mathbf{H B})$ and $\mathrm{Cu}\left(\mathrm{CH}_{3} \mathrm{CN}\right)_{4} \mathrm{PF}_{6}$ was stirred with 5.0 equivalents of terphenyl-alkyne $\mathbf{7}$ and -azide $\mathbf{8}$ in dichloromethane solution. Following chromatographic purification, rotaxanes 9.Se, 9.Te, and 9.HB were isolated in 56 $\%, 46 \%$ and $21 \%$ yields respectively (Scheme 3 ). Notably, during the active metal template reaction involving macrocycle 1.Te, another rotaxane analogue containing a single TeMe group was isolated $(21 \%)$, likely arising from the insertion of $\mathrm{Cu}(\mathrm{I})$ into the $\mathrm{C}$-Te bond of the telluro-triazole moiety after the formation of the rotaxane. ${ }^{30}$ It is noteworthy that a significantly lower yield $(21 \%)$ of the all-hydrogen bonding rotaxane analogue (9.HB) was obtained compared to 9.Se and 9.Te. This may be attributable to the contrasting modes of $\mathrm{Cu}(\mathrm{I})$ coordination by $\mathbf{1 . H B}$ and the $\mathrm{ChB}$ macrocycles, where the endotopic bidentate chalcogen- $\mathrm{Cu}(\mathrm{I})$ coordination of the latter favors rotaxane formation to a greater extent than the monodentate triazole $N$-coordination of $\mathrm{Cu}(\mathrm{I})$ for 1.HB. Conclusive NMR/MS spectroscopic evidence of the interlocked nature of rotaxanes 9.Se, 9.Te, and 9.HB is provided in the Supporting Information.

Anion Binding Studies of Neutral ChB Rotaxanes. Anion binding studies of the neutral rotaxanes 9.Se, 9.Te and 9.HB were performed using ${ }^{1} \mathrm{H}$ NMR titrations, where increasing quantities of anions, as their tetrabutylammonium (TBA) salts, were added to a solution of the rotaxane in $d_{6}$-acetone. ${ }^{61}$ As shown in Figure S5-1, addition of chloride to 9.Te resulted in large downfield shifts $\left(\Delta \delta=0.37 \mathrm{ppm}\right.$ after $10.0 \mathrm{Cl}^{-}$equivalents) of the axle triazole $\mathrm{H}_{3}$ proton resonance (proton assignments in Scheme 3), clearly showing its direct involvement with anion binding within the rotaxane cavity. Smaller upfield shifts in proton signals arising from $\mathrm{H}_{a}, \mathrm{H}_{1}, \mathrm{H}_{2}$ and $\mathrm{H}_{6}$ (see Scheme 3 for assignments) suggests that chloride anion binding results in changes to the rotaxane conformation. Although halide binding also resulted in downfield movements of the 
Scheme 3. Synthesis of Chalcogen Bonding Rotaxanes and their Hydrogen Bonding Analogue
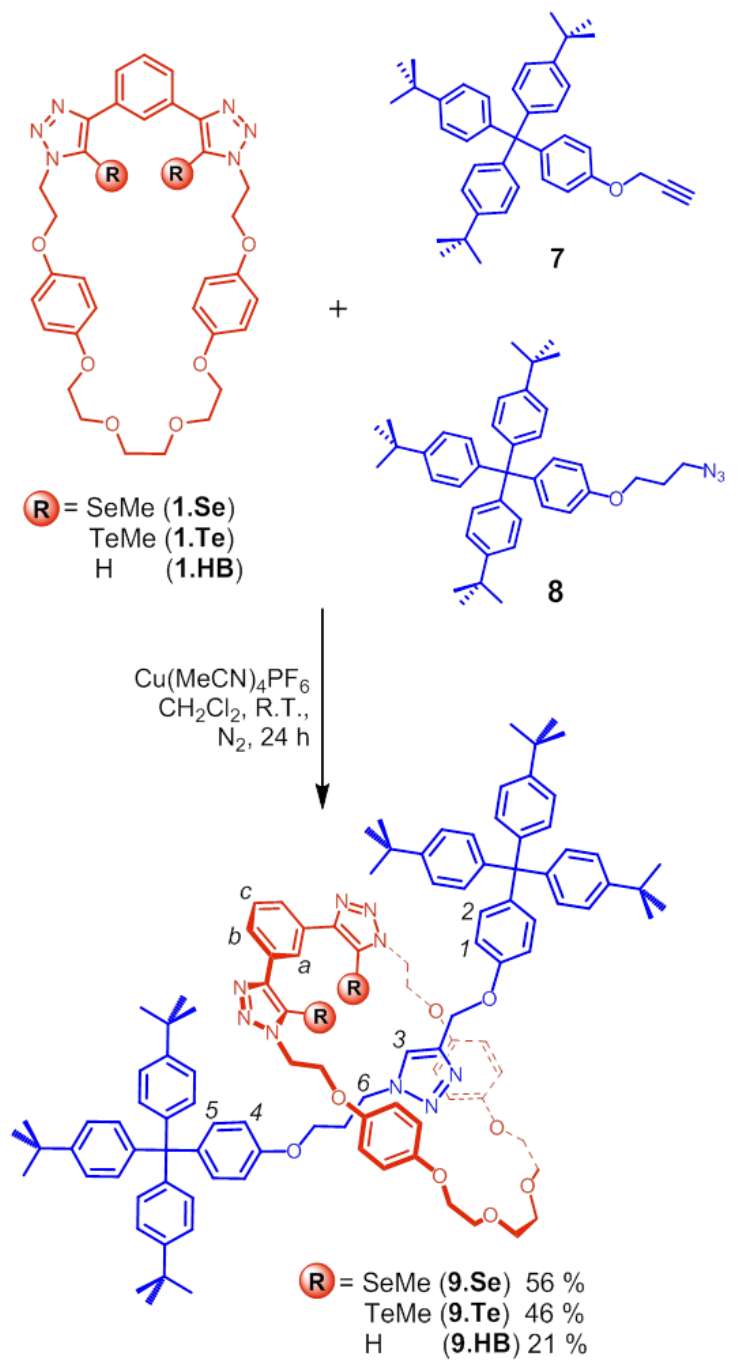

TeMe proton signals, the shifts seen were small $(\Delta \delta=0.06$ ppm after $10.0 \mathrm{Cl}^{-}$equivalents) compared with those of axle triazole $\mathrm{H}_{3}$, indicating that these methyl protons are not participating in significant hydrogen bonding interactions with the bound chloride anion. By monitoring the perturbations of the axle triazole resonance $\left(\mathrm{H}_{3}\right)$ as a function of chloride concentration, WinEQNMR2 analysis ${ }^{62}$ of the titration data determined 1:1 stoichiometric association constants shown in Table 1.

Rotaxane 9.Te displays a greater propensity for binding anions of higher charge density, as evident from the halides where progressively weaker binding was observed from fluoride to iodide. Notably, in spite of the steric bulk of the TeMe groups within the rotaxane binding cavity, 9.Te was able to bind anions differing greatly in size, ranging from fluoride to sulfate, ${ }^{63}$ as evident from the large downfield perturbations of the axle triazole proton seen in all cases. This is presumably due to the rotaxane's axle triazole component being able to adjust its position spatially within the macrocycle to accommodate the anion guest species. Due to its dianionic nature, sulfate forms the strongest association with 9.Te.
Most importantly, a comparison of the anion binding properties of 9.Te with the chalcogen-free analogue 9.HB serves to highlight the contributions of $\mathrm{ChB}$ interactions towards anion recognition. Other than appearing to stabilize the rotaxane structure from decomposition in the presence of $\mathrm{F}^{-}$and $\mathrm{SO}_{4}{ }^{2-}$ which occurred with $\mathbf{9 . H B}$, noticeably enhanced binding of chloride and bromide is displayed by 9.Te. As a related sigma hole-based non-covalent interaction to halogen bonding, which has been demonstrated to enhance the strength of anion binding over hydrogen bonding owing to its greater covalent character, ${ }^{64} \mathrm{ChB}$-anion interactions are thus shown to have comparable, and even slightly greater strength than the ubiquitous HB-anion interactions.

Table 1. Anion association constants $\left(K_{\mathrm{a}} / \mathrm{M}^{-1}\right)$ for Neutral Rotaxanes 9.Te and 9.HB in $d_{6}$-Acetone.

\begin{tabular}{ccc} 
Anion & \multicolumn{2}{c}{$K_{a} / \mathrm{M}^{-1}$} \\
\cline { 2 - 3 } & $\mathbf{9 . T e}$ & $\mathbf{9 . H B}$ \\
$\mathrm{F}^{-}$ & $360(35)^{b}$ & $-^{c}$ \\
$\mathrm{Cl}^{-}$ & $127(2)$ & $81(3)$ \\
$\mathrm{Br}^{-}$ & $110(2)$ & $65(5)$ \\
$\mathrm{I}^{-}$ & $34(3)$ & $43(1)$ \\
$\mathrm{AcO}^{-}$ & $98(2)$ & $-^{d}$ \\
$\mathrm{SO}_{4}{ }^{2-}$ & $1130(63)$ & $-{ }^{c}$
\end{tabular}

${ }^{a}$ Calculated using the WinEQNMR2 software, ${ }^{62}$ monitoring the axle triazole proton for both rotaxanes; errors $( \pm)$ in parentheses; [rotaxane] $=1.0 \mathrm{mM}, T=298 \mathrm{~K} .{ }^{b}$ Estimated value due to slight rotaxane decomposition seen in the presence of 10.0 equivalents of fluoride. ${ }^{c}$ Significant rotaxane decomposition occurred during titration. ${ }^{d}$ Not performed.

Encouraged by the strong binding displayed by sulfate for rotaxane 9.Te, sulfate binding was investigated using 9.Se in $d_{6}$-acetone as well. Surprisingly, while the addition of sulfate to 9.Se caused downfield shifts of its axle triazole proton in a similar manner as 9.Te, the binding was too weak for reliable association constant values to be determined (see Figure S5-4 in Supporting Information). With chloride, scant perturbations of the same proton environment could be discerned $\left(\Delta \delta=0.01 \mathrm{ppm}\right.$ after 10 equivalents of $\left.\mathrm{Cl}^{-}\right)$. Considering the structural similarity of both $\mathrm{ChB}$ rotaxanes, coupled with the fact that the anion binding site of 9.Se is slightly less sterically-crowded than 9.Te due to the smaller Se atoms, it is reasonable to assume that both anions would have been able to penetrate the binding cavity of 9.Se. The weak anion binding properties of 9.Se may thus be ascribed to the less polarisable nature and electropositivity of Se compared to Te, resulting in considerably weaker $\mathrm{ChB}$-anion interactions. More importantly, these findings give further credence that $\mathrm{ChB}$ interactions are dominating the anion binding observed in 9.Te, confirming that potential hydrogen bonding sites on existing functionalities within the rotaxane framework do not contribute significantly to its anion binding properties.

Synthesis of Cationic ChB Host Systems. In order to enhance the strength of ChB-anion interactions, especially important for anion binding studies performed in competitive aqueous solvent mixtures, macrocycle 1.Se, rotaxane 9.Se and their hydrogen bonding analogues were methylated at each 
triazole position (product structures shown in Chart 1). Double triazole methylation of 1.Se was successfully achieved using two equivalents of trimethyloxonium tetrafluoroborate in anhydrous dichloromethane to form the dicationic macrocycle 10.Se. Macrocycle 1.Te, on the other hand, showed significant lability of the TeMe groups under identical methylation reaction conditions, and no appreciable quantities of pure dicationic tellurium-containing macrocycle could be isolated. With the rotaxanes 9.Se and 9.HB, triple methylation at each triazole position was achieved using the same methylating agent at elevated temperatures for two weeks to afford tricationic rotaxanes 11.Se and 11.HB respectively, following chromatographic purification and anion exchange to the noncoordinating hexafluorophosphate $\left(\mathrm{PF}_{6}^{-}\right)$salts (see Supporting Information for full synthetic details). Seleno-triazole methylation resulted in significantly greater electron-deficiency of the selenium atoms, exemplified by macrocycle 10.Se where a large downfield shift of the ${ }^{77} \mathrm{Se}$ NMR signal $(\Delta \delta=+61.5$ ppm) was observed as compared to its neutral precursor. In addition, methylation also resulted in rotaxanes 11.Se and 11.HB being less conformationally dynamic than their neutral congeners, with a much larger splitting and desymmetrisation of both hydroquinone proton environments seen $(\Delta \delta=0.42$ ppm for 11.Se and $0.35 \mathrm{ppm}$ for 11.HB). Potentially, this arises from enhanced aromatic donor-acceptor interactions between macrocycle and axle, as well as hydrogen bonding interactions between the axle triazolium methyl group and the polyether segment of the macrocycle, rigidifying the rotaxane structure. $^{65}$ This is also expected to create a more well-defined and preorganised three-dimensional rotaxane anion binding cavity compared to their neutral precursors.

Single Crystal X-ray Diffraction Studies of ChB $\cdots$ Iodide Interactions. Single crystals of the iodide-complexed macrocycle 10.Se suitable for analysis with diffraction techniques were obtained by layered diffusion of diethyl ether into a solution of the macrocycle as its hexafluorophosphate salt and excess TBAI in chloroform/ acetonitrile 1:1 $(v / v)$. As the orange single crystals obtained were small and weaklydiffracting, diffraction data were collected using synchrotron radiation with I19-1 at Diamond Light Source. ${ }^{66}$

As iodide is the only counteranion present in the crystal structure of dicationic macrocycle 10.Se, the anion is present in a 2:1 ratio with the macrocycle to maintain charge neutrality. Although there is significant disorder, it is clear that both methylseleno-triazolium units are twisted out of plane relative to the central benzene ring, and are pointing in opposite directions as shown in Figure 3. This is likely to minimize the sterics arising from the bulky SeMe groups. As a result, the iodide anions are not bound convergently by the two Se atoms of the same macrocycle, but are interacting with SeMe groups on adjacent macrocycle units in the solid state. Importantly, the structure shows the dominance of chargeassisted $\mathrm{ChB}$ interactions in iodide coordination, as the only notable short contacts were observed between iodide and the Se atoms, despite the possibility of HB interactions with the electron-deficient triazolium $N$-methyl protons as well. In addition, the $\mathrm{C}-\mathrm{Se} \cdots \mathrm{I}^{-}$angles approach linear in each case, highlighting the influence of the $\sigma$-holes on the $s p^{3}$-hybridized
Se atoms in governing the geometry of the ChB-anion contacts as well as crystal packing.

\section{Chart 1. Structures of cationic ChB host systems and their HB analogues.}
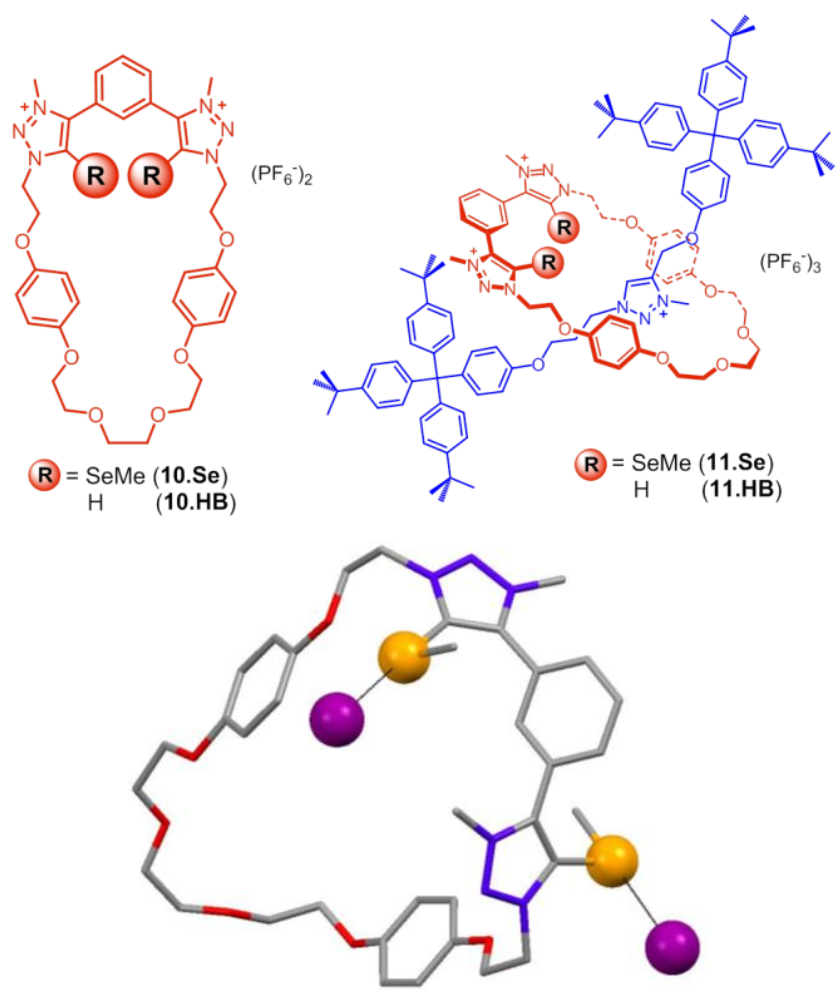

Figure 3. Crystal structure of the 10.Se-I adduct, showing the short $\mathrm{ChB}$ contacts between the $\mathrm{Se}$ atoms (orange) and the major component of the iodide anions (purple). Hydrogen atoms, solvent molecules and all the minor components of the disorder are omitted for clarity. Short $\mathrm{ChB}$ interactions are depicted with black dashed lines. Grey $=$ carbon, blue $=$ nitrogen and red $=$ oxygen.

Solution-phase Anion Binding with Charged-Assisted ChB Host Molecules. ${ }^{1} \mathrm{H}$ NMR anion binding studies on cationic macrocycle 10.Se, rotaxane 11.Se and their hydrogen bonding analogues were performed with chloride, bromide, iodide, sulfate and acetate, in aqueous solvent mixtures of either $2 \%$ $\mathrm{D}_{2} \mathrm{O}$ for the macrocycles ${ }^{67}$ and $20 \% \mathrm{D}_{2} \mathrm{O}$ water for the rotaxanes in $d_{6}$-acetone $(v / v)$.

For macrocycle 10.Se, addition of anions caused significant downfield perturbations of the signals arising from the aromatic proton in between both seleno-triazole moieties, as well as that of the methylene protons immediately adjacent to the triazoliums (see Figure S5-4 in Supporting Information). In the presence of halide anions, tricationic rotaxane 11.Se exhibited numerous shifts of its ${ }^{1} \mathrm{H}$ NMR spectrum diagnostic of anion binding proximal to the interlocked rotaxane cavity. For instance, very large downfield perturbations of the axle triazolium proton environment $\left(\mathrm{H}_{3}\right)$ were observed, evident of direct hydrogen bonding with the anion, concomitantly 
with increased splitting of the hydroquinone resonances (Figure 4A). Downfield shifts of signals arising from stopper proton $\mathrm{H}_{4}$ of the axle suggested that the halides were bound slightly above the plane of the macrocycle (vide infra), most likely arising from the out-of-plane twist of the cationic methylseleno-triazole moieties as noted in the crystal structure of macrocycle 10.Se. Finally, small movements of the triazolium $\mathrm{N}$-methyl protons of the macrocycle component were seen, consistent with the halides not being bound on the external periphery of the rotaxane structure.

In contrast with the halides, addition of the oxoanions sulfate and acetate to 11.Se gave rise to very small shifts of axle triazolium $\mathrm{H}_{3}$. However, large upfield perturbations of axle stopper protons (such as $\mathrm{H}_{4}$ ) were seen, suggesting that these oxoanions were associating on the rotaxane cavity periphery (Figure 4B). On the other hand, the chalcogen-free tricationic rotaxane analogue 11.HB showed significant downfield shifts of axle triazolium $\mathrm{H}_{3}$ as well as the internal aromatic proton environment $\mathrm{H}_{\mathrm{a}}$ of the macrocycle with these oxoanions, indicative of binding within the interlocked cavity (see Supporting Information). Evidently, the bulky methylselenium subunits of rotaxane 11.Se exert considerable steric influence on its anion binding properties, resulting in sulfate and acetate being too large to fit into the sterically-crowded rotaxane binding site.

Table 2 summarizes the 1:1 stoichiometric association constants determined using WinEQNMR2 analysis ${ }^{62}$ of the titration data. ${ }^{68} \mathrm{~A}$ comparison of the anion binding properties of the cationic $\mathrm{ChB}$ host systems (10.Se and 11.Se) with their $\mathrm{HB}$ analogues in the presence of water revealed notable differences. For both 10.Se and 11.Se, a distinct Hofmeister bias for anion binding can be seen amongst the halides, with anion affinities decreasing in the order $\mathrm{I}^{-}>\mathrm{Br}^{-}>\mathrm{Cl}^{-}$. In contrast, selectivity for $\mathrm{Br}^{-}$was obtained for 11.HB, with 10.HB also showing considerably enhanced affinity for $\mathrm{Br}^{-}$over $\mathrm{I}^{-}$. The trend obtained for the $\mathrm{ChB}$ host systems mirror those known for halogen bonding in the presence of water, ${ }^{69-71}$ due to the intrinsic similarity of the nature of these $\sigma$-hole-based interactions, favoring binding of the 'softer', more lipophilic and more easily-desolvated heavier halides. While it has been noted that sulfate is unable to penetrate the rotaxane binding site of 11.Se, analysis of the shifts of proton $\mathrm{H}_{4}$ on the rotaxane stopper groups during the anion titrations revealed a remarkably strong interaction, which is surprising given that sulfate is amongst the most strongly hydrated anions known. ${ }^{63}$ This implies that to some extent, Coulombic attractions are making a significant contribution to the anion binding event. Amongst all the anions studied, acetate showed the largest difference in binding behavior between 11.Se and 11.HB, with more than two orders of magnitude enhancement in association constant values seen with the hydrogen bonding host. Most likely resulting mainly from size-mismatch with the binding cavity of 11.Se as noted before, the stark anion recognition contrasts also highlight the fundamental differences in sensitivity to anion basicity between $\mathrm{ChB}$ and $\mathrm{HB}$ host systems.

Having demonstrated the important influences of $\mathrm{ChB}$ interactions on the anion binding properties of macrocycle 10.Se and rotaxane 11.Se, DFT and Molecular Dynamics simulations were performed to offer further insights into the conformational changes, geometries and solvation effects on anion binding. Initial studies were performed through the DFT optimizations of model host-guest anion complexes using an

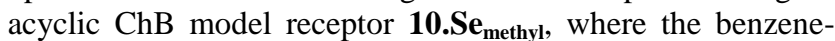
1,3-bis(methylseleno-triazolium) binding motif of 10.Se was capped with two methyl groups. The halide $\left(\mathrm{Cl}^{-}, \mathrm{Br}^{-}\right.$and $\left.\mathrm{I}^{-}\right)$ complexes of $\mathbf{1 0 . S e} \mathbf{e}_{\text {methyl }}$ were DFT optimized with the M06$2 \mathrm{X}$ functional, using the aug-cc-pVDZ-PP basis set for $\mathrm{Se}, \mathrm{Br}$ and I, the aug-cc-pVDZ basis set for $\mathrm{Cl}$, and the $6-311++\mathrm{G}^{* *}$
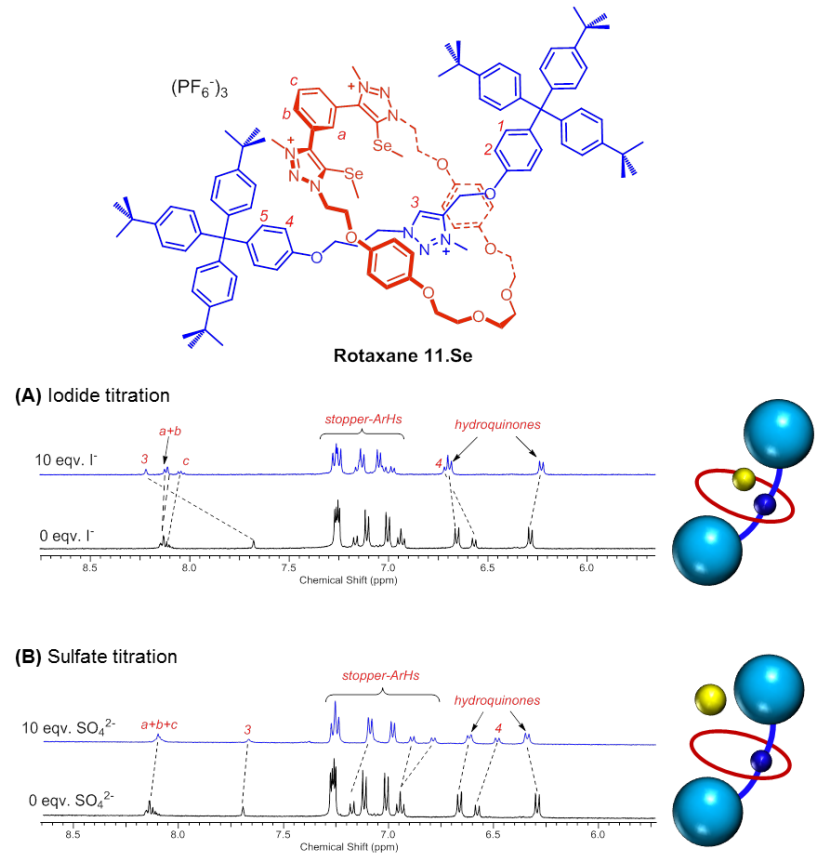

Figure 4. Partial ${ }^{1} \mathrm{H}$ NMR spectra of rotaxane 11.Se showing the changes to its aromatic region with the addition of 10 equivalents of $(A)$ iodide and $(B)$ sulfate $\left([\mathbf{1 1 . S e}]=1.0 \mathrm{mM}, \mathrm{d}_{6}\right.$-acetone/ $\mathrm{D}_{2} \mathrm{O}$ $4: 1, \mathrm{~T}=298 \mathrm{~K})$.

Table 2. Anion association constants $\left(K_{\mathrm{a}} / \mathrm{M}^{-1}\right)$ for Cationic 10.Se, 10.HB, 11.Se and 11.HB. ${ }^{a}$

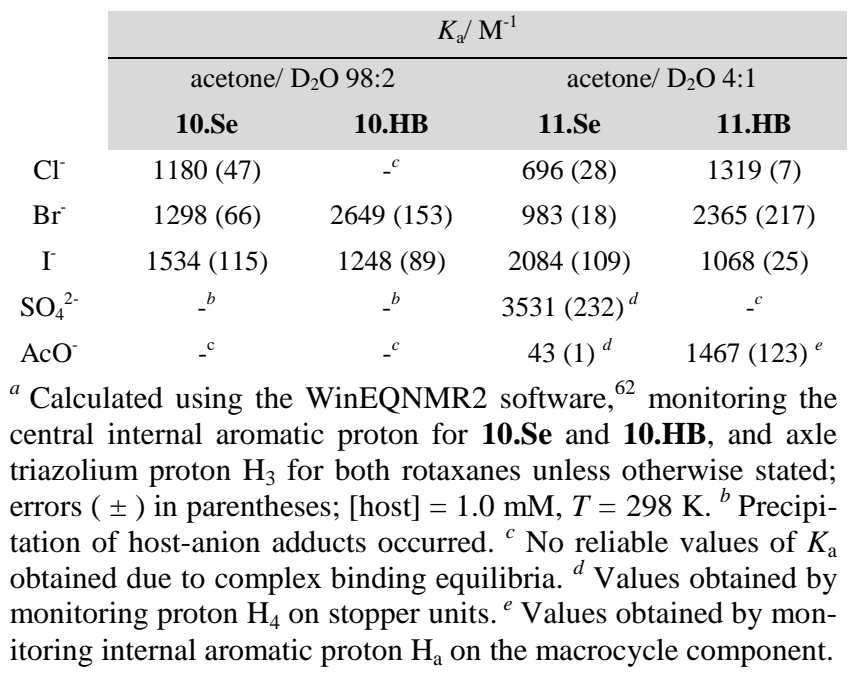


basis set for the remaining atoms. These calculations were carried out in gas phase given that there is no standard approach to include the solvent effects of an acetone/water mixture in pure QM calculations. The DFT optimized structures

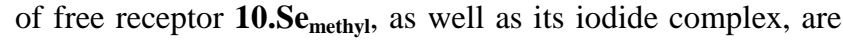
presented in Figure 5, along with their electrostatic potential distributions. Equivalent illustrations for the chloride and bromide associations are shown in Figure S7-2.
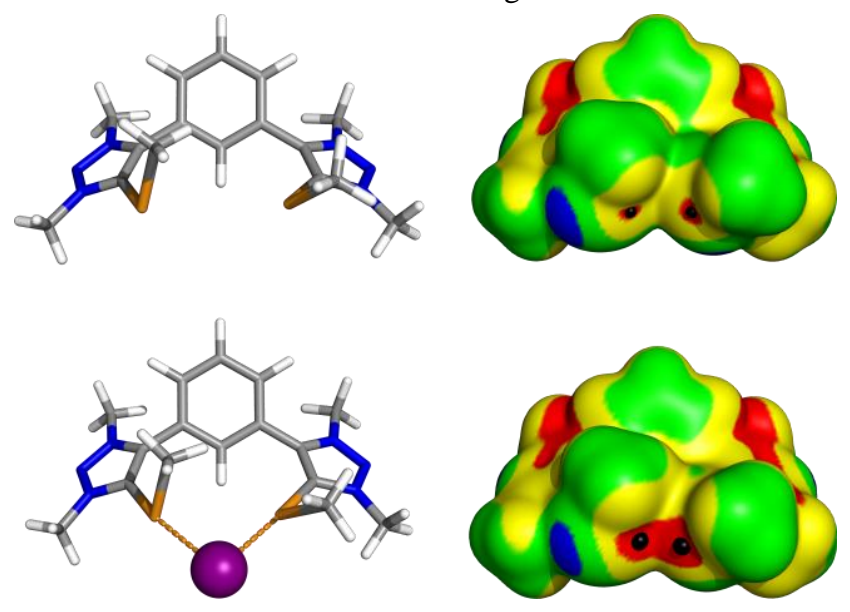

Figure 5. Structural and electronic features obtained by DFT

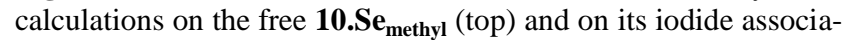
tion (bottom). Left: Optimized structures. Right: Distribution of the electrostatic potential mapped onto the electron density surface of $\mathbf{1 0 . S e} \mathbf{m}_{\text {methyl }}$ or after removal of the halide. The chalcogen bonds are drawn as orange dashed lines and the halide is drawn as purple sphere. The location of each $\mathrm{V}_{\mathrm{S} \text {, max }}$ is represented as a black dot, and corresponds to the $\sigma$-hole in front of each $\mathrm{SeMe}$ binding unit. The color ranges, in $\mathrm{kJ} / \mathrm{mol}$, are as follows: blue below 470.7; green - between 470.7 and 533.5; yellow - between 533.5 and 596.2; red - above 596.2.

As shown in Figure 5, model receptor $\mathbf{1 0 . S e _ { \text { methyl } }}$ binds to each halide anion via two cooperative $\mathrm{ChB}$ interactions differing slightly in lengths that increase with the size of the halide $\left(\mathrm{Cl}^{-}: 2.804,2.870 \AA\right.$; $\mathrm{Br}^{-}: 2.963,3.015 \AA$; and $\mathrm{I}^{-}$: 3.166, $3.244 \AA$ ). In addition, the $\mathrm{C}_{\text {triazolium }}$-Se-halide bond angles range from 168.5 to $177.1^{\circ}$, which deviate only slightly from linearity akin to halogen bonding, the sister $\sigma$-hole interaction. For free $\mathbf{1 0 . S e} \mathbf{e}_{\text {methyl }}$, the distribution of the electrostatic potential mapped onto the electron density surface shows two narrow separated positive regions (in red) which surround the most electron deficient site (in black) located at the termini of each $\mathrm{C}_{\text {triazolium }}$-Se bond (see Figure 5, top right). Interestingly, the presence of the halide induces a greater electron deficiency at the binding site, resulting in an increase in the $V_{\mathrm{S}, \max }$ of approximately $33.42 \mathrm{~kJ} \mathrm{~mol}^{-1}$ on the Se atoms compared to the free receptor, with the relevant $\mathrm{ChB}$ dimensions for the

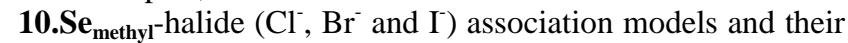
individual $V_{\mathrm{S}, \max }$ values summarized in Tables S7-3 and S7-4, respectively. This structural analysis shows that $\mathrm{ChB}$ interactions can be subjected to similar computational treatments as their sister $\sigma$-hole-based halogen bonding interactions.

From the DFT optimized structures of the $\mathbf{1 0 . S e} \mathbf{e}_{\text {methyl }}$-halide complexes, we were able to estimate the
Wiberg Bond Indices (WBI) of the ChB-halide interactions. Generally, heavier halides gave larger independent WBI values, increasing in the order $\mathrm{Cl}^{-}(0.189 ; 0.153)<\mathrm{Br}^{-}(0.199$; $0.167)<\mathrm{I}^{-}(0.213 ; 0.167)$, with the values in parentheses representing the WBI for each $\mathrm{ChB}$-halide interaction. These findings suggested that $\mathrm{ChB}$-anions interactions with the heavier halides have a larger degree of covalent character, which may partly explain the greater anion affinities of 10.Se and 11.Se observed for the heavier halides (Table 2).

After demonstrating the linearity of the ChB-anion interactions, classical molecular dynamics (MD) simulations were performed to investigate the anion associations with receptors 10.Se and 11.Se in their respective solvent mixtures. The ChB interactions were simulated using an extra point of charge to represent the $\sigma$-hole found in front of each $\mathrm{C}$-Se activated bond as shown in Figure 5, in a similar way as our previous work on halogen bonding anion recognition by interlocked host systems. ${ }^{69,71-73}$ In addition, force field bonding parameters involving the selenium center were developed to be used together with the General Amber Force Field (GAFF). ${ }^{74,75}$ These unprecedented parameterizations are detailed in the Supporting Information.

The initial model of rotaxane 11.Se was generated from a crystal structure of a previously-published rotaxane containing an iodotriazolium axle, ${ }^{76}$ by replacing the existing macrocycle component with 10.Se while maintaining the orthogonal binding pocket and the roughly parallel disposition between the axle's triazolium ring and the macrocycle's hydroquinone motifs. The axle triazolium methyl group was orientated towards the polyether oxygen atoms of the macrocycle, establishing stabilizing $\mathrm{C}-\mathrm{H} \cdots \mathrm{O}$ hydrogen bonding interactions with them. With each guest anion positioned above the macrocycle plane in front of both $\mathrm{Se}$ atoms, the 11.Se-anion complexes, initially optimized by molecular mechanics (MM) in gas phase, were immersed in a cubic box composed of 1802 and 1836 randomly-distributed acetone and water molecules (acetone/ water 4:1 v/v) respectively, in accordance with the ${ }^{1} \mathrm{H}$ NMR binding studies (Table 2). The same procedure was also performed for gas-phase MM energy-minimized structures of both free and anion-complexed macrocycle 10.Se in a cubic box comprising 84 water and 1005 acetone molecules (acetone/ water 98:2 v/v). To maintain charge neutrality, a suitable number of $\mathrm{PF}_{6}^{-}$counteranions was added to each solvated complex. The dynamical behavior of each anion complex was further ascertained through three independent MD runs of $50 \mathrm{~ns}$ for $\mathbf{1 0 . S e}$ and 11.Se, carried out under periodic conditions using a NPT ensemble and AMBER 16 (PMEMD), ${ }^{77}$ with GPU acceleration, ${ }^{78-80}$ as simulation engine (see Supporting Information).

The distance between each halide (A) and the center of mass of the macrocycle component, taking into account only the non-hydrogen atoms $\left(\mathrm{MAC}_{\text {cent }}\right)$, was monitored along the simulation time of each MD run, together with individual chalcogen bond dimensions ( $\mathrm{Se} \cdots \mathrm{A}$ distance and $\mathrm{C}_{\text {triazolium }}{ }^{-}$ $\mathrm{Se} \cdot \mathrm{A}$ angle). The average values of these structural parameters for three MD runs are listed in Table 3, while Table 4 lists the number of solvent molecules found within a $3.5 \AA$ radius around the two Se centers and each halide anion when free and complexed. For rotaxane 11.Se, the additional hydrogen bonding interaction between the axle triazolium proton $\left(\mathrm{H}_{3}\right)$ 
and each halide, evident from the ${ }^{1} \mathrm{H}$ NMR titration studies in Figure 4, was simulated using weak harmonic restraints on the $\mathrm{C} \cdots \mathrm{A}$ distance and $\mathrm{C}-\mathrm{H} \cdots \mathrm{A}$ angle throughout the MD runs, affording the values listed in Table 3 .

Figure 6 (top) shows a representative snapshot of the 11.Se-iodide complex taken from the MD runs, while equivalent binding scenarios for chloride and bromide are shown in the Supporting Information (Figure S7-3). The $\mathrm{A} \cdots \mathrm{MAC}_{c e n t}$ distances for the 11.Se-halide complexes indicate that anion binding occurs above the plane of the macrocycle with chloride closest to the rotaxane's binding pocket, and the larger bromide and iodide anions being progressively further away. The halide anions are kept bonded to 11.Se by two convergent $\mathrm{ChB}$ interactions along the three MD runs, which are only occasionally interrupted, as suggested by the small standard deviations of the $\mathrm{Se} \cdot \mathrm{A}$ A $\left(\mathrm{A}=\mathrm{Cl}^{-}, \mathrm{Br}^{-}\right.$or $\left.\mathrm{I}^{-}\right)$distances (see Table 3). The two ChB-halide interactions are nearly linear throughout the $50 \mathrm{~ns}$ simulations, with the average $\mathrm{C}_{\text {triazolium- }}$ Se $\cdots \mathrm{A}$ angles around $170^{\circ}$. Generally, the average $\mathrm{Se} \cdots \mathrm{A}$ distances mirror the trend from the earlier model acyclic $\mathrm{ChB}$ receptor $\mathbf{1 0 . S e} \mathbf{e}_{\text {methyl }}$. For macrocycle 10.Se, two simultaneous $\mathrm{ChB}$ interactions were also maintained with the halide guest positioned above the macrocycle plane throughout most of the simulation time, as illustrated in Figure 6 (bottom). Notably, the average Se...A distances for 10.Se were longer than those for 11.Se, accompanied by larger standard deviation values (Table 3). This indicated that the chalcogen bonds of the 10.Se-halide complexes were more frequently broken.

Our MD simulations also showed the crucial roles played by hydration in determining the halide binding selectivity trends of 10.Se and 11.Se. As shown in Table 4, the $\mathrm{ChB}$-donor SeMe groups of both free host molecules are preferentially solvated by acetone molecules, with very few water molecules $(\leq 0.3)$ surrounding them initially. However, binding of the halide anions is accompanied by an increase in the average number of water molecules around the SeMe groups for both host systems, with smaller and more hydrophilic halides hydrating the SeMe groups to a larger extent, while simultaneously displacing more acetone molecules initially present. Significantly, this increases the competition between the more hydrated halides and water molecules for interaction with the SeMe binding sites, making it more likely for water molecules to disrupt the ChB-anion interactions. Accordingly, the heavier halides allow more sustained chalcogen bonds due to smaller extent of disruption by the surrounding water molecules, together with the higher degree of covalency of $\mathrm{ChB}$ interactions suggested by the WBI calculations, resulting in the higher binding affinities experimentally observed.

Finally, our computational results also offer insights on the observed superiority of rotaxane 11.Se over macrocycle 10.Se for anion binding, seen in Table 2 where comparable binding affinities were obtained for both $\mathrm{ChB}$ hosts despite the much greater competitiveness of the solvent used for 11.Se. As aforementioned, 11.Se is able to host the anions within its three dimensional binding pocket, with shorter A $\cdots \mathrm{MAC}_{\text {cent }}$ distances as compared to 10.Se (Table 3). As shown in Table 4 , this not only results in more extensive halide dehydration upon binding as the anions are less exposed to the water molecules, but also a smaller resulting degree of hydration of each host's binding cavity (smaller number of water molecules around the SeMe groups). ${ }^{81}$ Concomitantly, the ChB-anion interactions of 11.Se are subjected to less extensive interruptions by the water molecules in close proximity, and hence leads to higher anion affinities compared to 11.Se. Naturally, other structural factors also contribute to the superior halide binding of 11.Se, including the higher net charge, the hydrogen bond between the axle triazolium proton and halides, as well as the pre-organized binding cavity of this rotaxane-host system. It is notable, however, that these computational findings provide the first glimpse of the important roles played by the solvent, in particular water, in determining the anion binding affinity and selectivity of ChB host systems.
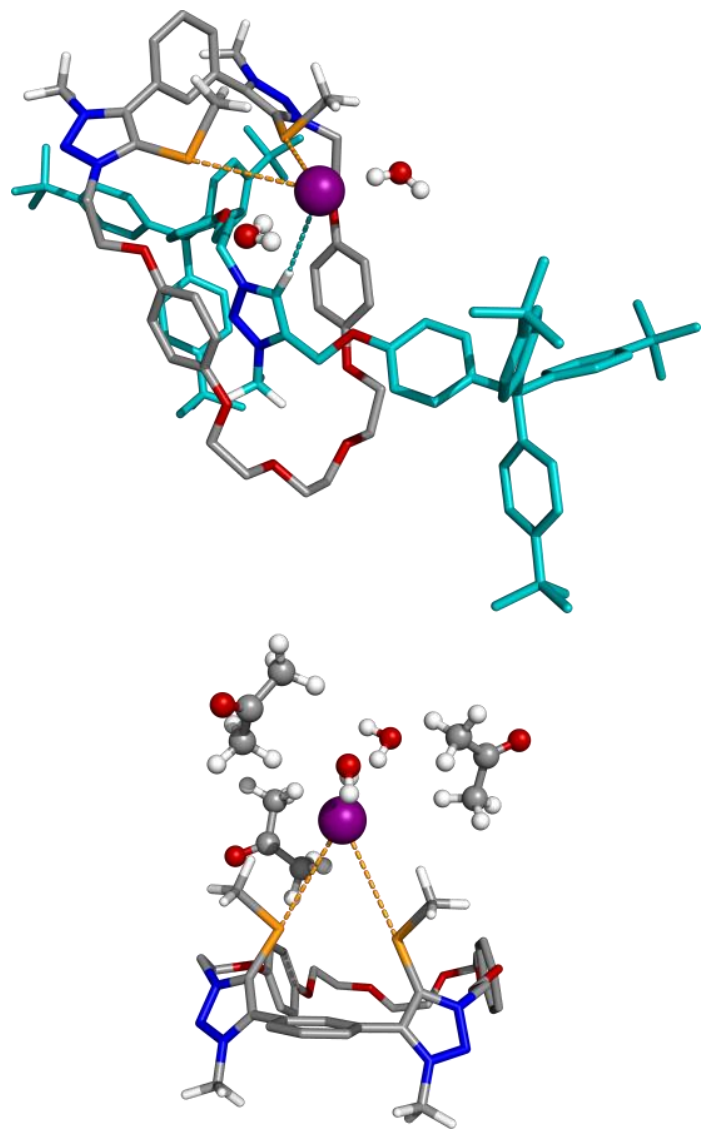

Figure 6. Illustrative snapshot of the 11.Se-(top) and 10.Se(bottom) iodide complexes, showing the anion surrounded by several solvent molecules. The anion is bound by two chalcogen bonds (orange dashed lines), which are assisted by a single $\mathrm{C}_{\text {tria- }}$ zolium $-\mathrm{H} \cdots \mathrm{I}$ - hydrogen bond (teal dashed line) in the rotaxane.

Probing Halide Anion Binding by Heteronuclear ${ }^{77} \mathrm{Se}$ and ${ }^{125}$ Te NMR. Having established the involvement of chalcogen bonding interactions in the anion binding behavior of 9.Te, 10.Se and 11.Se, heteronuclear ${ }^{77}$ Se and ${ }^{125}$ Te NMR was used to monitor anion binding. Both nuclei, despite their moderately low natural abundances, are highly sensitive to changes in their electronic and structural environments, ${ }^{82,83}$ and hence have found applications as responsive probes to study metal complexation, ${ }^{84,85}$ secondary bonding interactions with Lewis bases, ${ }^{21}$ non-covalent interactions in solution ${ }^{14,86}$ and even changes in chemical environments following conformational changes and encapsulation in biotic ${ }^{87}$ and abiotic systems. ${ }^{88} \mathrm{In}$ 
Table 3. Average ChB and HB dimensions obtained from MD simulations of the halide complexes of 10.Se and 11.Se, along with the distances between the halide guests and the center of mass of the macrocycle in either system. ${ }^{a, b}$

\begin{tabular}{|c|c|c|c|c|c|c|c|c|}
\hline \multirow[b]{2}{*}{ Anion } & \multicolumn{5}{|c|}{ 11.Se $e^{c}$} & \multicolumn{3}{|c|}{ 10.Se ${ }^{c}$} \\
\hline & $\mathrm{Se} \cdots \mathrm{A}$ & $\begin{array}{l}\angle \mathrm{C}_{\text {triazolium }}{ }^{-} \\
\text {Se } \cdots \mathrm{A}\end{array}$ & $\mathrm{C}_{\text {axle }} \cdots \mathrm{A}$ & $\angle \mathrm{C}_{\mathrm{axle}}-\mathrm{H} \cdots \mathrm{A}$ & $\mathrm{A} \cdots \mathrm{MAC}_{c e n t}{ }^{d}$ & $\mathrm{Se} \cdots \mathrm{A}$ & $\begin{array}{l}\angle \mathrm{C}_{\text {triazolium }}{ }^{-} \\
\text {Se } \cdots \mathrm{A}\end{array}$ & $\mathrm{A} \cdots \mathrm{MAC}_{c e n t}{ }^{d}$ \\
\hline $\mathrm{Cl}^{-}$ & $\begin{array}{c}3.712 \pm 0.214 \\
; \\
3.700 \pm 0.213\end{array}$ & $\begin{array}{c}170.3 \pm 4.0 \\
170.7 \pm 3.9\end{array}$ & $\begin{array}{c}3.765 \pm \\
0.188\end{array}$ & $134.5 \pm 15.2$ & $4.462 \pm 0.520$ & $\begin{array}{c}3.759 \pm 0.240 \\
3.740 \pm 0.232\end{array}$ & $\begin{array}{c}169.0 \pm 4.6 \\
169.3 \pm 4.5\end{array}$ & $5.714 \pm 0.582$ \\
\hline $\mathrm{Br}^{-}$ & $\begin{array}{c}4.017 \pm 0.261 \\
; \\
4.027 \pm 0.268\end{array}$ & $\begin{array}{c}170.3 \pm 4.6 \\
170.2 \pm 4.6\end{array}$ & $\begin{array}{c}3.941 \pm \\
0.191\end{array}$ & $135.8 \pm 14.1$ & $4.805 \pm 0.536$ & $\begin{array}{c}4.070 \pm 0.313 \\
4.088 \pm 0.318\end{array}$ & $\begin{array}{c}168.2 \pm 5.6 \\
167.9 \pm 5.7\end{array}$ & $6.040 \pm 0.673$ \\
\hline $\mathrm{I}^{-}$ & $\begin{array}{c}4.317 \pm 0.274 \\
; \\
4.316 \pm 0.280\end{array}$ & $\begin{array}{c}169.6 \pm 5.1 \\
169.8 \pm 5.1\end{array}$ & $\begin{array}{l}4.141 \pm \\
0.193\end{array}$ & $135.9 \pm 15.9$ & $5.163 \pm 0.644$ & $\begin{array}{c}4.422 \pm 0.332 \\
4.403 \pm 0.323\end{array}$ & $\begin{array}{c}167.1 \pm 6.3 \\
167.5 \pm 6.1\end{array}$ & $6.380 \pm 0.676$ \\
\hline
\end{tabular}

a) The values for the individual MD runs are given in Tables S7-5 to S7-8 (see Supporting Information); ${ }^{b)}$ All distances and angles are given in $\AA$ and $\left({ }^{\circ}\right)$, respectively. ${ }^{c)} N=150000 ;{ }^{d)}$ as defined in the text.

Table 4. Number of solvent (water and acetone) molecules around the SeMe binding units and halides in MD simulations of free and anion-complexed 11.Se or 10.Se. ${ }^{a, b}$

\begin{tabular}{|c|c|c|c|c|c|c|c|c|}
\hline \multirow{4}{*}{ Complex } & \multicolumn{4}{|c|}{ 11.Se } & \multicolumn{4}{|c|}{ 10.Se } \\
\hline & \multicolumn{2}{|c|}{ SeMe binding units } & \multicolumn{2}{|c|}{ Halide guest } & \multicolumn{2}{|c|}{ SeMe binding units } & \multicolumn{2}{|c|}{ Halide guest } \\
\hline & $\begin{array}{c}\mathrm{N}^{\mathrm{o}} \text { of water } \\
\text { molecules }\end{array}$ & $\begin{array}{c}\mathrm{N}^{\mathrm{o}} \text { of acetone } \\
\text { molecules }\end{array}$ & $\begin{array}{l}\mathrm{N}^{\mathrm{o}} \text { of water } \\
\text { molecules }\end{array}$ & $\begin{array}{c}\mathrm{N}^{\mathrm{o}} \text { of acetone } \\
\text { molecules }\end{array}$ & $\begin{array}{c}\mathrm{N}^{\mathrm{o}} \text { of water } \\
\text { molecules }\end{array}$ & $\begin{array}{c}\mathrm{N}^{\mathrm{o}} \text { of acetone } \\
\text { molecules }\end{array}$ & $\begin{array}{l}\mathrm{N}^{\mathrm{o}} \text { of water } \\
\text { molecules }\end{array}$ & $\begin{array}{l}\mathrm{N}^{\circ} \text { of acetone } \\
\text { molecules }\end{array}$ \\
\hline & $\operatorname{Avg} \pm \mathrm{SD}$ & $\operatorname{Avg} \pm \mathrm{SD}$ & $\operatorname{Avg} \pm \mathrm{SD}$ & $\operatorname{Avg} \pm \mathrm{SD}$ & $\operatorname{Avg} \pm \mathrm{SD}$ & $\operatorname{Avg} \pm \mathrm{SD}$ & $\mathrm{Avg} \pm \mathrm{SD}$ & $\operatorname{Avg} \pm \mathrm{SD}$ \\
\hline Unbound & $0.3 \pm 0.6$ & $1.1 \pm 0.9$ & -- & -- & $0.1 \pm 0.2$ & $2.4 \pm 1.1$ & -- & -- \\
\hline $\mathrm{Cl}^{-}$ & $0.8 \pm 0.8$ & $0.3 \pm 0.5$ & $4.0 \pm 0.9$ & $0.5 \pm 0.7$ & $0.9 \pm 0.8$ & $1.5 \pm 0.9$ & $3.3 \pm 1.0$ & $2.1 \pm 1.1$ \\
\hline $\mathrm{Br}^{-}$ & $0.5 \pm 0.7$ & $0.5 \pm 0.6$ & $3.6 \pm 1.0$ & $0.9 \pm 0.8$ & $0.5 \pm 0.6$ & $1.6 \pm 0.9$ & $2.4 \pm 1.0$ & $2.5 \pm 1.1$ \\
\hline $\mathrm{I}^{-}$ & $0.2 \pm 0.5$ & $0.7 \pm 0.6$ & $2.4 \pm 1.1$ & $1.0 \pm 0.9$ & $0.2 \pm 0.4$ & $1.8 \pm 0.9$ & $1.0 \pm 0.9$ & $2.3 \pm 1.2$ \\
\hline
\end{tabular}

a) The values for the individual MD runs are given in Tables S7-9 and S7-10 (see Supporting Information); ${ }^{b)} N=150000$.

an attempt to correlate the perturbations of the ${ }^{77} \mathrm{Se}$ and ${ }^{125} \mathrm{Te}$ NMR signals with the anion association constant values determined from ${ }^{1} \mathrm{H}$ NMR titrations, the heteronuclear spectra of 9.Te, 10.Se and 11.Se were obtained in the presence of 10 equivalents of halides in the same solvent mixtures as the ${ }^{1} \mathrm{H}$ NMR titrations (Tables 1 and 2).

As shown in Table 5, halide binding to rotaxane 9.Te in $\mathrm{d}_{6}$-acetone resulted in large upfield shifts of the ${ }^{125} \mathrm{Te}$ NMR signal by almost 8 ppm in the case of chloride, which decreases in magnitude with decreasing halide binding affinity (Table 1). Interestingly, an excellent linear correlation $\left(\mathrm{R}^{2}=\right.$ 0.996) of the magnitude of ${ }^{125} \mathrm{Te}$ shifts with $1 / r^{2}$, with $r$ being the anionic radii of the halide, was observed (see Supporting Information, Figure S6-1). ${ }^{63}$ This implies that the charge density of the halide guest plays an important role in influencing the electronic properties of the Te atoms.

Analogous ${ }^{77} \mathrm{Se}$ NMR titration experiments with cationic $\mathrm{ChB}$ hosts 10.Se and 11.Se in acetone/ $\mathrm{D}_{2} \mathrm{O}$ aqueous solvent mixtures, in stark contrast, revealed the reverse trend in the relationship between the halide-bound induced shift magnitudes of ${ }^{77} \mathrm{Se}$ signal shift and $K_{\mathrm{a}}$ values. Despite chloride being the weakest-bound halide in both cases (Table 2), it was still able to elicit the largest upfield perturbations of the ${ }^{77} \mathrm{Se}$ signals for both selenium-containing hosts. Iodide, on the other hand, consistently resulted in the smallest changes to the ${ }^{77}$ Se resonances despite displaying the greatest binding affinity. While it is tempting to attribute this trend to the charge density of the halide bound in a similar way as 9.Te, a com- parison of the ${ }^{1} \mathrm{H}$ NMR shifts observed during the titrations of 10.Se and 11.Se suggests that the actual situation is far more complex. For instance, the magnitude of the ${ }^{1} \mathrm{H}$ NMR signals shifts for 10.Se followed the trend of $\mathrm{Cl}^{-}>\mathrm{Br}^{-}>\mathrm{I}^{-}$, in accordance with expectations from charge density arguments alone, while the reverse trend was seen for 11.Se (see binding isotherms in Supporting Information), despite both hosts showing the greatest binding affinity for iodide. Hence, a complex multitude of inter-related factors, likely involving contributions from anion charge density, spatial separation between the Se atoms and anions arising from different accessibilities of the binding cavity (Table 3), as well as changes in solvation of the SeMe groups on anion binding (Table 4), all play a part in changing the local electronic environment of the Se atoms which affect the magnitudes of the resulting ${ }^{77} \mathrm{Se}$ NMR signal perturbations. While our present study highlights the sensitivity of heteronuclear chalcogen NMR to anion binding, further studies involving a greater number of $\mathrm{ChB}$ host molecules are required before any trends can be conclusively discerned. 
Table 5. Shifts $(\Delta \delta / \mathrm{ppm})$ of ${ }^{125}$ Te and ${ }^{77}$ Se NMR resonances of 9.Te, 10.Se and 11.Se in the presence of 10.0 equivalents of halides. ${ }^{a}$

\begin{tabular}{cccc} 
& \multicolumn{3}{c}{$\Delta \delta / \mathrm{ppm}$} \\
\cline { 2 - 4 } $\mathrm{Cl}^{-}$ & $\mathbf{9 . T e ^ { b }}$ & $\mathbf{1 0 . S e}$ & $\mathbf{1 1 . S e}^{c}$ \\
$\mathrm{Br}^{-}$ & -7.7 & -5.1 & -7.3 \\
$\mathrm{I}^{-}$ & -5.8 & -4.6 & -6.3 \\
& -2.8 & -2.5 & -2.0
\end{tabular}

${ }^{a} \Delta \delta=\delta_{10 \text { eqv halide }}-\delta_{0 \text { eqv halide }} ;[$ host $]=4.0 \mathrm{mM}, T=298 \mathrm{~K} .{ }^{b}$ Solvent $=$ pure $d_{6}$-acetone, $\delta_{\mathrm{Te}, 0}$ eqv halide $=116.5 \mathrm{ppm} ;{ }^{c}$ Solvent $=d_{6^{-}}$ acetone/ $\mathrm{D}_{2} \mathrm{O}=98: 2, \delta_{\mathrm{Se}, 0 \text { eqv halide }}=106.9 \mathrm{ppm} ;{ }^{d}$ Solvent $=d_{6^{-}}$ acetone $/ \mathrm{D}_{2} \mathrm{O}=4: 1, \delta_{\mathrm{Se}, 0 \text { eqv halide }}=105.2 \mathrm{ppm}$.

\section{CONCLUSIONS}

Exploiting the air and moisture-stable methylchalcogenotriazole motif, the repertoire of $\mathrm{ChB}$ host molecules has been considerably expanded by the synthesis of the first examples of neutral and cationic $\mathrm{ChB}$ macrocycles and rotaxanes. The chalcogen atoms have been shown to exhibit two fundamentally antagonistic properties: acting as Lewis basic donor ligands for metal cation binding (e.g. $\mathrm{Cu}^{+}$), and functioning as Lewis acids for anion binding via their $\sigma$-holes. ${ }^{1} \mathrm{H}$ NMR binding studies performed in organic and aqueous solvent mixtures confirm that $\mathrm{ChB}$-anion binding affinity can rival, and even exceed that of hydrogen bonding exhibited by all hydrogen bonding receptor analogues. In aqueous solvent mixtures, charge-assisted ChB-mediated halide anion binding displays a Hofmeister bias favoring binding of larger halides. Computational modelling suggests that this trend likely arises due to the larger degree of covalency with the heavier halides, as well as the smaller degree of hydration of the anion binding site. Furthermore, using heteronuclear ${ }^{125} \mathrm{Te}$ and ${ }^{77} \mathrm{Se}$ NMR spectroscopy, we have demonstrated that the chemical shifts of the chalcogen atoms are highly sensitive to anion binding. The unique stability of methylchalcogeno-triazoles as a ChBdonor motif, coupled with their distinctive steric and geometric requirements for anion binding, thus sets the stage for their further exploitation in selective binding and sensing of biologically and environmentally-relevant anionic guest species.

\section{ASSOCIATED CONTENT}

\section{Supporting Information}

Detailed synthetic procedures for compounds, characterization data, anion binding isotherms, as well as data for X-ray crystallography and computational modelling are provided. The Supporting Information is available free of charge on the ACS Publications website.

\section{AUTHOR INFORMATION}

\section{Corresponding Author}

* paul.beer@chem.ox.ac.uk

\section{Author Contributions}

The manuscript was written through contributions of all authors. / All authors have given approval to the final version of the manuscript.

\section{ACKNOWLEDGMENT}

J.Y.C.L thanks the Agency for Science, Technology and Research, Singapore, for postgraduate funding. I.M. thanks the FCT for the $\mathrm{PhD}$ scholarship SFRH/BD/87520/2012. The authors would like to acknowledge the Diamond Light Source for beamtime on the I19 beamline (MT13639). The theoretical studies were supported by projects P2020-PTDC/QEQ-SUP/4283/2014, CICECO - Aveiro Institute of Materials (FCT UID/CTM/50011/2013) and iBiMED - Institute of Biomedicine (FCT UID/BIM/04501/2013), financed by National Funds through the FCT/MEC and, when applicable, co-financed by FEDER through COMPETE, under the PT2020 Partnership Agreement.

\section{REFERENCES}

(1) Gilday, L. C.; Robinson, S. W.; Barendt, T. A.; Langton, M. J.; Mullaney, B. R.; Beer, P. D. Chem. Rev. 2015, 115 (15), 7118 7195 .

(2) Cavallo, G.; Metrangolo, P.; Milani, R.; Pilati, T.; Priimagi, A.; Resnati, G.; Terraneo, G. Chem. Rev. 2016, 116 (4), 2478-2601.

(3) Bauzá, A.; Alkorta, I.; Frontera, A.; Elguero, J. J. Chem. Theory Comput. 2013, 9 (11), 5201-5210.

(4) Bauza, A.; Quinonero, D.; Deya, P. M.; Frontera, A. CrystEngComm 2013, 15 (16), 3137-3144.

(5) Bauzá, A.; Mooibroek, T. J.; Frontera, A. ChemPhysChem 2015, 16 (12), 2496-2517.

(6) Nziko, V. de P. N.; Scheiner, S. J. Phys. Chem. A 2014 118 (45), 10849-10856.

(7) Birman, V. B.; Li, X. Org. Lett. 2006, 8 (7), 1351-1354.

(8) Fukumoto, S.; Nakashima, T.; Kawai, T. Angew. Chem. Int. Ed. 2011, 50 (7), 1565-1568.

(9) Leverett, C. A.; Purohit, V. C.; Romo, D. Angew. Chem. Int. Ed. 2010, 49 (49), 9479-9483.

(10) Fanfrlík, J.; Přáda, A.; Padělková, Z.; Pecina, A.; Macháček, J.; Lepšík, M.; Holub, J.; Růžička, A.; Hnyk, D.; Hobza, P. Angew. Chem. Int. Ed. 2014, 53 (38), 10139-10142.

(11) Cozzolino, A. F.; Elder, P. J. W.; Vargas-Baca, I. Recent Trends Main Group Chem. 2011, 255 (11-12), 1426-1438.

(12) Benz, S.; Macchione, M.; Verolet, Q.; Mareda, J.; Sakai, N.; Matile, S. J. Am. Chem. Soc. 2016, 138 (29), 9093-9096.

(13) Kremer, A.; Fermi, A.; Biot, N.; Wouters, J.; Bonifazi, D. Chem. - Eur. J. 2016, 22 (16), 5665-5675.

(14) Ho, P. C.; Szydlowski, P.; Sinclair, J.; Elder, P. J. W.; Kübel, J.; Gendy, C.; Lee, L. M.; Jenkins, H.; Britten, J. F.; Morim, D. R.; Vargas-Baca, I. Nat. Commun. 2016, 7, 11299.

(15) Cozzolino, A. F.; Whitfield, P. S.; Vargas-Baca, I. J. Am. Chem. Soc. 2010, 132 (48), 17265-17270.

(16) Nagao, Y.; Hirata, T.; Goto, S.; Sano, S.; Kakehi, A.; Iizuka, K.; Shiro, M. J. Am. Chem. Soc. 1998, 120 (13), 3104-3110.

(17) Brown, A.; Beer, P. D. Chem Commun 2016, 52 (56), $8645-8658$.

(18) Beale, T. M.; Chudzinski, M. G.; Sarwar, M. G.; Taylor, M. S. Chem Soc Rev 2013, 42 (4), 1667-1680.

(19) Garrett, G. E.; Gibson, G. L.; Straus, R. N.; Seferos, D. S.; Taylor, M. S. J. Am. Chem. Soc. 2015, 137 (12), 4126-4133.

(20) Garrett, G. E.; Carrera, E. I.; Seferos, D. S.; Taylor, M. S. Chem Commun 2016, 52 (64), 9881-9884.

(21) Zhao, H.; Gabbaï, F. P. Nat Chem 2010, 2 (11), 984-990.

(22) Chivers, T.; Laitinen, R. S. Chem Soc Rev 2015, 44 (7), $1725-1739$. 
(23) Park, H.; Edgar, L. J.; Lumba, M. A.; Willis, L. M.; Nitz, M. Org Biomol Chem 2015, 13 (25), 7027-7033.

(24) Crowley, J. D.; Goldup, S. M.; Lee, A.-L.; Leigh, D. A.; McBurney, R. T. Chem Soc Rev 2009, 38 (6), 1530-1541.

(25) White, N. G.; Lovett, H. G.; Beer, P. D. RSC Adv 2014, 4 (24), 12133-12147.

(26) Li, Y.; Flood, A. H. Angew. Chem. Int. Ed. 2008, 47 (14), 2649-2652.

(27) Wang, W.; Peng, X.; Wei, F.; Tung, C.-H.; Xu, Z. Angew. Chem. Int. Ed. 2016, 55 (2), 649-653.

(28) Ding, S.; Jia, G.; Sun, J. Angew. Chem. Int. Ed. 2014, 53 (7), 1877-1880.

(29) Stefani, H. A.; Silva, N. C. S.; Vasconcelos, S. N. S.; Manarin, F.; Souza, F. B. Tetrahedron Lett. 2013, 54 (22), 2809-2812.

(30) Stefani, H. A.; Vasconcelos, S. N. S.; Manarin, F.; Leal, D. M.; Souza, F. B.; Madureira, L. S.; Zukerman-Schpector, J.; Eberlin, M. N.; Godoi, M. N.; de Souza Galaverna, R. Eur. J. Org. Chem. 2013, 2013 (18), 3780-3785.

(31) Brotherton, W. S.; Clark, R. J.; Zhu, L. J. Org. Chem. 2012, 77 (15), 6443-6455.

(32) Upon the synthesis of 6.Te, stability studies performed using ${ }^{1} \mathrm{H}$ NMR experiments in $d_{6}$-DMSO showed that the tellurotriazoles units were stable for at least 7 days in solution under ambient conditions without any evidence of decomposition (see Supporting Information).

(33) Worrell, B. T.; Hein, J. E.; Fokin, V. V. Angew. Chem. Int Ed. 2012, 51 (47), 11791-11794.

(34) The lower yields of macrocycle 1.Te compared to 1.Se was due to the thermal lability of the C-Te bond, as some loss of $\mathrm{TeCH}_{3}$ groups were observed during the ring-closing reaction. Hence, we attempted other conditions to achieve ring-closing using 2.Te and $\mathbf{3}$ without the need for heating, such as using sodium hydride as base in THF. It is notable that successful ring-closing was only observed using the presently reported conditions of $\mathrm{Cs}_{2} \mathrm{CO}_{3}$ in DMF with heating.

(35) Barat, R.; Legigan, T.; Tranoy-Opalinski, I.; Renoux, B.; Peraudeau, E.; Clarhaut, J.; Poinot, P.; Fernandes, A. E.; Aucagne, V.; Leigh, D. A.; Papot, S. Chem Sci 2015, 6 (4), 2608-2613.

(36) Bordoli, R. J.; Goldup, S. M. J. Am. Chem. Soc. 2014, 136 (13), 4817-4820.

(37) Campbell, C. J.; Leigh, D. A.; Vitorica-Yrezabal, I. J.; Woltering, S. L. Angew. Chem. Int. Ed. 2014, 53 (50), 13771-13774.

(38) Weisbach, N.; Baranova, Z.; Gauthier, S.; Reibenspies, J. H.; Gladysz, J. A. Chem Commun 2012, 48 (61), 7562-7564.

(39) Aucagne, V.; Berná, J.; Crowley, J. D.; Goldup, S. M.; Hänni, K. D.; Leigh, D. A.; Lusby, P. J.; Ronaldson, V. E.; Slawin, A. M. Z.; Viterisi, A.; Walker, D. B. J. Am. Chem. Soc. 2007, 129 (39), 11950-11963.

(40) Neal, E. A.; Goldup, S. M. Chem Sci 2015, 6 (4), 23982404.

(41) Lewis, J. E. M.; Winn, J.; Cera, L.; Goldup, S. M. J. Am. Chem. Soc. 2016, 138 (50), 16329-16336.

(42) Movsisyan, L. D.; Franz, M.; Hampel, F.; Thompson, A. L.; Tykwinski, R. R.; Anderson, H. L. J. Am. Chem. Soc. 2016, 138 (4), 1366-1376.

(43) Baranová, Z.; Amini, H.; Bhuvanesh, N.; Gladysz, J. A. Organometallics 2014, 33 (23), 6746-6749.

(44) Winn, J.; Pinczewska, A.; Goldup, S. M. J. Am. Chem. Soc. 2013, 135 (36), 13318-13321.

(45) Berná, J.; Crowley, J. D.; Goldup, S. M.; Hänni, K. D.; Lee, A.-L.; Leigh, D. A. Angew. Chem. Int. Ed. 2007, 46 (30), 5709 5713.

(46) Goldup, S. M.; Leigh, D. A.; Lusby, P. J.; McBurney, R. T.; Slawin, A. M. Z. Angew. Chem. Int. Ed. 2008, 47 (18), 33813384.

(47) Goldup, S. M.; Leigh, D. A.; McBurney, R. T.; McGonigal, P. R.; Plant, A. Chem Sci 2010, 1 (3), 383-386.
(48) Fleischel, O.; Wu, N.; Petitjean, A. Chem Commun 2010, 46 (44), 8454-8456.

(49) Monkowius, U.; Ritter, S.; König, B.; Zabel, M.; Yersin, H. Eur. J. Inorg. Chem. 2007, 2007 (29), 4597-4606.

(50) Mishra, S.; Jeanneau, E.; Daniele, S. 2009 Young Investig. Spec. Issue 2010, 29 (1), 500-506.

(51) Ritch, J. S.; Chivers, T. Inorg. Chem. 2009, 48 (8), $3857-$ 3865 .

(52) Kimani, M. M.; Wang, H. C.; Brumaghim, J. L. Dalton Trans 2012, 41 (17), 5248-5259.

(53) Black, J. R.; Champness, N. R.; Levason, W.; Reid, G. Inorg. Chem. 1996, 35 (15), 4432-4438.

(54) Kimani, M. M.; Bayse, C. A.; Brumaghim, J. L. Dalton Trans 2011, 40 (14), 3711-3723.

(55) Poropudas, M. J.; Vigo, L.; Oilunkaniemi, R.; Laitinen, R. S. Dalton Trans 2013, 42 (48), 16868-16877.

(56) M. J. Frisch, G.; Trucks, W.; Schlegel, H. B.; Scuseria, G. E.; Robb, M. A.; Cheeseman, J. R.; Scalmani, G.; Barone, V.; Mennucci, B.; Petersson, G. A.; Nakatsuji, H.; Caricato, M.; Li, X.; Hratchian, H. P.; Izmaylov, A. F.; Bloino, J.; Zheng, G.; Sonnenberg, J. L. Gaussian 09, Revision A. 1; Gaussian; 2009; pp 2009-2009.

(57) Schuchardt, K. L.; Didier, B. T.; Elsethagen, T.; Sun, L.; Gurumoorthi, V.; Chase, J.; Li, J.; Windus, T. L. J. Chem. Inf. Model. 2007, 47 (3), 1045-1052.

(58) Feller, D. J. Comput. Chem. 1996, 17 (13), 1571-1586.

(59) Miertuš, S.; Scrocco, E.; Tomasi, J. Chem. Phys. 1981, 55 (1), 117-129.

(60) Groom, C. R.; Bruno, I. J.; Lightfoot, M. P.; Ward, S. C. Acta Crystallogr. Sect. B Struct. Sci. Cryst. Eng. Mater. 2016, 72 (2), 171-179.

(61) Analogous ${ }^{1} \mathrm{H}$ NMR titrations in $\mathrm{d}_{6}$-acetone showed no evidence of chloride binding for neutral macrocycle 1.Se. Due to solubility issues, chloride titrations with 1.Te could only be performed in $\mathrm{CD}_{2} \mathrm{Cl}_{2}$ and $\mathrm{d}_{6}$-DMSO, which revealed no perturbations of any proton environments in either solvent.

(62) Hynes, M. J. J. Chem. Soc. Dalton Trans. 1993, No. 2 $311-312$.

(63) Marcus, Y. J Chem Soc Faraday Trans 1991, 87 (18), 2995-2999.

(64) Robinson, S. W.; Mustoe, C. L.; White, N. G.; Brown, A.; Thompson, A. L.; Kennepohl, P.; Beer, P. D. J. Am. Chem. Soc. 2015, 137 (1), 499-507.

(65) Mercurio, J. M.; Knighton, R. C.; Cookson, J.; Beer, P. D. Chem. - Eur. J. 2014, 20 (37), 11740-11749.

(66) Single crystal X-ray diffraction data for 10.Se-I were collected with synchrotron radiation using I19-1 at Diamond Light Source $(\lambda=0.6889 \AA)$. [REF2] Cell parameters were determined and refined and raw frame data were integrated using CrysAlisPro. The structure was solved with SuperFlip [REF3] and refined by fullmatrix least squares on $F^{2}$ using CRYSTALS [REF4]. Single Crystal Data: $\mathrm{C}_{36} \mathrm{H}_{44} \mathrm{I}_{2} \mathrm{~N}_{6} \mathrm{O}_{6} \mathrm{Se}_{2}, \mathrm{I}_{2}, 0.928\left(\mathrm{C}_{2} \mathrm{H}_{3} \mathrm{~N}\right), M_{r}=4415.49$, monoclinic, $\mathbf{P} 2_{1} / c=22.6944(7) \AA, \quad b=21.4972(5) \AA, \quad c=9.4414(3) \AA$, $\beta=99.847(3)^{\circ}, \quad V=4538.3(2) \AA, \quad$ data/restraints/parameters: $9208 / 1878 / 716, R_{\text {int }}=11.4 \%$, final $R_{1}=6.83 \%, w R_{2}=17.67 \%$ $(I>2 \sigma(I)), \Delta \rho_{\min , \max }=-1.34,+2.66 \mathrm{e} . \AA^{3}$. Crystallographic data (excluding structure factors) have been deposited with the Cambridge Crystallographic Data Centre (CCDC 1521870) and copies of these data can be obtained free of charge via www. ccdc.cam.ac.uk/data_request/cif.

(67) More competitive solvents containing greater quantities of water could not be used for anion titrations using macrocycle 10.Se, as the perturbations of the various proton environments were too small for reliable values of association constants to be determined.

(68) Unless otherwise stated in Table 2, the ${ }^{1} \mathrm{H}$ NMR titrations show all anions investigated associate with the cationic host molecules in a 1:1 stoichiometry, with no evidence of a second anion binding event. 
(69) Langton, M. J.; Marques, I.; Robinson, S. W.; Félix, V.; Beer, P. D. Chem. - Eur. J. 2016, 22 (1), 185-192.

(70) Lim, J. Y. C.; Beer, P. D. Chem. Commun. 2015, 51 (17), $3686-3688$.

(71) Langton, M. J.; Robinson, S. W.; Marques, I.; Félix, V.; Beer, P. D. Nat Chem 2014, 6 (12), 1039-1043.

(72) Barendt, T. A.; Docker, A.; Marques, I.; Félix, V.; Beer, P. D. Angew. Chem. Int. Ed. 2016, 55 (37), 11069-11076.

(73) Lim, J. Y. C.; Marques, I.; Ferreira, L.; Felix, V.; Beer, P. D. Chem Commun 2016, 52 (32), 5527-5530.

(74) Wang, J.; Wolf, R. M.; Caldwell, J. W.; Kollman, P. A.; Case, D. A. J. Comput. Chem. 2004, 25 (9), 1157-1174.

(75) Wang, J.; Wolf, R. M.; Caldwell, J. W.; Kollman, P. A.; Case, D. A. J. Comput. Chem. 2005, 26 (1), 114-114.

(76) Kilah, N. L.; Wise, M. D.; Serpell, C. J.; Thompson, A. L.; White, N. G.; Christensen, K. E.; Beer, P. D. J. Am. Chem. Soc. 2010, 132 (34), 11893-11895.

(77) Case, D. A.; Betz, R. M.; Botello-Smith, W.; Cerutti, D. S.; Cheatham III, T. E.; Darden, T. A.; Duke, R. E.; Giese, T. J.; Gohlke, H.; Goetz, A. W.; Homeyer, N.; Izadi, S.; Janowski, P.; Kaus, J.; Kovalenko, A.; Lee, T. S.; LeGrand, S.; Li, P.; Lin, C.; Luchko, T.; Luo, R.; Madej, B.; Mermelstein, D.; Merz, K. M.; Monard, G.; Nguyen, H.; Nguyen, H. T.; Omelyan, I.; Onufriev, A.; Roe, D. R.; Roitberg, A.; Sagui, C.; Simmerling, C. L.; Swails, J.; Walker, R. C.; Wang, J.; Wolf, R. M.; Wu, X.; Xiao, L.; York, D. M.; Kollman, P. A. University of California: San Francisco 2016.

(78) Salomon-Ferrer, R.; Götz, A. W.; Poole, D.; Le Grand, S.; Walker, R. C. J. Chem. Theory Comput. 2013, 9 (9), 3878-3888.
(79) Götz, A. W.; Williamson, M. J.; Xu, D.; Poole, D.; Le Grand, S.; Walker, R. C. J. Chem. Theory Comput. 2012, 8 (5), $1542-1555$.

(80) Le Grand, S.; Götz, A. W.; Walker, R. C. Comput. Phys. Commun. 2013, 184 (2), 374-380.

(81) The average number of water molecules enclosing each free anion in the two solvent mixtures was also assessed by MD simulations, being $4.7 \pm 0.9\left(\mathrm{Cl}^{-}\right), 3.5 \pm 1.2\left(\mathrm{Br}^{-}\right)$, and $1.6 \pm 1.0\left(\mathrm{I}^{-}\right)$in the acetone/water 98:2 solvent mixture used in the binding studies of 10.Se, while in the acetone/water 4:1 solvent mixture used for 11.Se these values increase to $6.9 \pm 1.1\left(\mathrm{Cl}^{-}\right), 6.3 \pm 1.2\left(\mathrm{Br}^{-}\right)$, and $4.8 \pm 1.3$ $\left(\mathrm{I}^{-}\right)$.

(82) Ronconi, L.; Sadler, P. J. Appl. NMR Inorg. Organomet. Chem. 2008, 252 (21-22), 2239-2277.

(83) Duddeck, H. In Annual Reports on NMR Spectroscopy; Academic Press, 2004; Vol. Volume 52, pp 105-166.

(84) Singh, A. K.; Sharma, S. Coord. Chem. Rev. 2000, 209 (1), 49-98.

(85) Smiles, D. E.; Wu, G.; Hrobárik, P.; Hayton, T. W. J. Am. Chem. Soc. 2016, 138 (3), 814-825.

(86) Viger-Gravel, J.; Meyer, J. E.; Korobkov, I.; Bryce, D. L. CrystEngComm 2014, 16 (31), 7285-7297.

(87) Schaefer, S. A.; Dong, M.; Rubenstein, R. P.; Wilkie, W. A.; Bahnson, B. J.; Thorpe, C.; Rozovsky, S. J. Mol. Biol. 2013, 425 (2), 222-231.

(88) Custelcean, R.; Bonnesen, P. V.; Duncan, N. C.; Zhang, X.; Watson, L. A.; Van Berkel, G.; Parson, W. B.; Hay, B. P. J. Am. Chem. Soc. 2012, 134 (20), 8525-8534. 
Authors are required to submit a graphic entry for the Table of Contents (TOC) that, in conjunction with the manuscript title, should give the reader a representative idea of one of the following: A key structure, reaction, equation, concept, or theorem, etc., that is discussed in the manuscript. Consult the journal's Instructions for Authors for TOC graphic specifications.

Insert Table of Contents artwork here

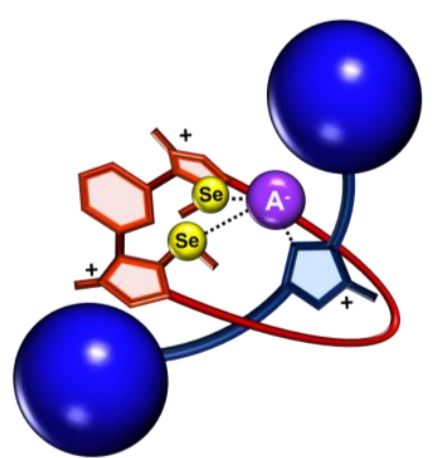

